\title{
Diurnal cycle of the dust instantaneous direct radiative forcing over the Arabian Peninsula
}

\author{
S. Osipov ${ }^{1}$, G. Stenchikov ${ }^{1}$, H. Brindley ${ }^{2}$, and J. Banks ${ }^{2}$ \\ ${ }^{1}$ King Abdullah University of Science and Technology, Thuwal, Saudi Arabia \\ ${ }^{2}$ Imperial College, London, UK \\ Correspondence to: S. Osipov (serega.osipov@gmail.com)
}

Received: 17 January 2015 - Published in Atmos. Chem. Phys. Discuss.: 24 April 2015

Revised: 13 August 2015 - Accepted: 17 August 2015 - Published: 27 August 2015

\begin{abstract}
In this study we attempted to better quantify radiative effects of dust over the Arabian Peninsula and their dependence on input parameters. For this purpose we have developed a stand-alone column radiation transport model coupled with the Mie, T-matrix and geometric optics calculations and driven by reanalysis meteorological fields and atmospheric composition. Numerical experiments were carried out for a wide range of aerosol optical depths, including extreme values developed during the dust storm on 18-20 March 2012. Comprehensive ground-based observations and satellite retrievals were used to estimate aerosol optical properties, validate calculations and carry out radiation closure. The broadband surface albedo, fluxes at the bottom and top of the atmosphere as well as instantaneous dust radiative forcing were estimated both from the model and observations. Diurnal cycle of the shortwave instantaneous dust direct radiative forcing was studied for a range of aerosol and surface characteristics representative of the Arabian Peninsula. Mechanisms and parameters responsible for diurnal variability of the radiative forcing were evaluated. We found that intrinsic variability of the surface albedo and its dependence on atmospheric conditions, along with anisotropic aerosol scattering, are mostly responsible for diurnal effects.
\end{abstract}

\section{Introduction}

Mineral dust is an important and integral part of the Earth system. Dust aerosol perturbs radiation balance by changing optical properties of the atmosphere (Claquin et al., 2011; Sokolik and Toon, 1999; Myhre et al., 2013). It affects cloud microphysical properties and precipitation devel- opment (Solomos et al., 2011; Levin et al., 1996; Miller et al., 2004), changes radiative heating of the surface and the atmosphere, causes significant alterations in the dynamics of the atmosphere (Cuesta et al., 2009; Cavazos-Guerra and Todd, 2012) and thus drives the circulation (Miller and Tegen, 1998; Bangalath and Stenchikov, 2015). Deposition of dust into the ocean provides a source of nutrients to the marine ecosystems (Krishnamurthy et al., 2010; Mahowald et al., 2005). Health hazards and air quality are directly linked to the presence of dust in the atmosphere (Derbyshire, 2007; Prospero, 1999). Ongoing effort to assess dust impacts on the past and future climate will help to reduce existing uncertainties. Significant progress has been achieved in understanding the mechanism of dust generation and emitted particle size distribution (Kok, 2011a, b; Kok et al., 2012; Shao et al., 2011). Improvement of dust mass balance and more accurate description of aerosol microphysical properties and vertical profiles have facilitated better understanding of the dynamic responses and quantification of dust radiative forcing (Zhao et al., 2013; Zhang et al., 2013; Koffi et al., 2012).

The world's biggest deserts are the major source regions of dust (Tanaka and Chiba, 2006; Ginoux et al., 2012). Multiple studies and field campaigns were conducted in North Africa, which accounts for more than $50 \%$ of the annual global dust emissions. Otto et al. (2007) carried out a sensitivity study on refractive index, solar zenith angle and surface albedo (ocean and desert) for the 1997 Saharan ACE-2 campaign. They stressed the role of large mineral dust particles. Slingo et al. (2006) presented simultaneous space and ground-based observations of a major dust storm during March 2006 in Niamey, Niger. Osborne et al. (2011) demonstrated the effect of Saharan dust aerosol in cloud-free conditions over land 
areas between Mauritania and Niger during June 2007. Ryder et al. (2013) investigated the aerosol size distribution and optical properties over Mali, Mauritania and Algeria during the Fennec 2011 aircraft campaign.

The Arabian Peninsula is the third largest source region of dust after North Africa and Central and East Asia, accounting for about $12 \%$ of total emissions (Tanaka and Chiba, 2006). However, this region has received little attention so far; it is lacking field campaigns and has few in situ observations. Some of the studies conducted for the Arabian Peninsula include dust storm trajectories analysis (Notaro et al., 2013), impact of the March 2009 dust storm (Maghrabi et al., 2011) and assessment of the remotely sensed and groundbased aerosol optical depth (AOD, $\tau$ ) measurements consistency (Yu et al., 2013).

Osborne et al. (2011), Slingo et al. (2006) and Otto et al. (2007) have considered diurnal effects of dust. However, treatment of the surface optical properties was oversimplified (surface albedo was fixed). Jin et al. (2004) showed that measured broadband ocean surface albedo (OSA) for a specific condition varies from about 0.04 at local noon to 0.3 when the sun is low. Li et al. (2006) considered several OSA parameterization schemes and pointed out that top of the atmosphere (TOA) reflected solar fluxes are biased by up to $20 \mathrm{~W} \mathrm{~m}^{-2}$ for simpler schemes. For the desert surface case, based on the Baseline Surface Radiation Network (BSRN) measurements at the Desert Rock location, Roesch et al. (2004) showed that diurnal variation of the broadband albedo were confined to the 0.2 to 0.27 range. Surface albedo is also known to depend on the atmospheric conditions and on the ratio of direct and diffuse fluxes in particular. Increased surface diffuse flux tends to increase effective albedo during the local solar noon and decrease it when the sun is low (Lyapustin, 1999). Even though intrinsic variability of the surface albedo and impact of atmospheric conditions are believed to have a minor effect on climate energy balance, diurnal cycle of the surface albedo may be an important factor in determining the sign and improving the quantitative estimate of dust forcing.

Daytime cycles of dust impact have also been studied using the observations from the Spinning Enhanced Visible and Infrared Imager (SEVIRI) and Geostationary Earth Radiation Budget (GERB) instruments on Meteosat-9, by Ansell et al. (2014) and Banks et al. (2014). In each considered case (Geostationary Earth Radiation Budget Intercomparison of Longwave and Shortwave radiation campaign over North Africa during June 2007 and Fennec campaign in the central Sahara in June 2011, respectively), diurnal features reported were generally not due to diurnal cycle of the AOD itself, suggesting that the physics involved play a major role.

The complexity of the mineral dust radiative effect is associated with several factors. Dust aerosol is optically active in both shortwave (SW) and longwave (LW) ranges. It is one of the most absorbing aerosols after black carbon (Kinne et al., 2003). Its effect strongly depends on a number of parameters including dust particle size distribution and surface albedo, temperature and water vapor mixing ratio, especially for the longwave case. Dust spatial, temporal and microphysical patterns are known to vary, depending on the location and source regions (Giles et al., 2012; Basart et al., 2009).

The current study aims at better quantification of the clearsky mineral dust instantaneous direct radiative forcing (DRF) and its diurnal cycle over the Arabian Peninsula. This region is less studied and lacks in situ observations, even though it represents one of the major sources of dust and occupies a significant part of the dust belt area (Prospero et al., 2002). We pay close attention to the effects of the surface albedo, carefully define aerosol characteristics and study the DRF diurnal cycle. In order to carry out numerical experiments, we developed a flexible framework for a stand-alone column Rapid Radiative Transfer Model (RRTM) and tested the model, conducting radiation closure calculations using satellite and ground-based observations. The model description is given in Sect. 2. Numerical experiments were performed for King Abdullah University of Science and Technology (KAUST) campus location at the shoreline of the Red Sea, $22.305^{\circ} \mathrm{N}, 39.095^{\circ} \mathrm{E}$ and at the Solar Village location in the central part of the Arabian Peninsula, 24.907 ${ }^{\circ} \mathrm{N}, 46.397^{\circ} \mathrm{E}$, where both bottom of the atmosphere (BOA) and top of the atmosphere (TOA) observations (Sect. 3) are available for closure as well as Aeronet observations of aerosol abundance and optical characteristics. Results are presented in Sect. 4. Mechanisms and parameters responsible for sensitivity of the diurnally resolved and daily mean DRF over the Arabian Peninsula are then discussed. We formulate conclusions in Sect. 5.

\section{Model description}

Column stand-alone radiative transfer models are widely used for detailing the radiative impact of dust aerosol (Otto et al., 2007; Osborne et al., 2011; Slingo et al., 2006). Such models comprise a radiative transfer core and a preprocessor. As a core of such a model, in this study we use the Rapid Radiative Transfer Model (RRTM), which is employed as a radiation module in a number of general circulation and regional models. The full list of applications, source code and examples are available at: http://rtweb.aer.com/rrtm_frame. html, last access: 17 January 2015. The developed preprocessor can handle

1. meteorological input profiles from ERA-Interim products or GCMs output

2. gas component profiles from observations and from chemistry and transport model outputs

3. spectral aerosol optical property profiles derived from Aeronet products

4. cloud property profiles (not used in this study) 
5. surface spectral optical properties from airplane observations, MODIS land products and parameterizations

In-depth details of each component and treatment of aerosols are given in the following sections.

\subsection{RRTM}

RRTM has been extensively validated and is known to be used in various applications including the Integrated Forecast System at the European Centre for Medium-Range Weather Forecasts (ECMWF) and the Weather Research and Forecasting Model (WRF-ARW) at the National Center for Atmospheric Research (NCAR). The LW module, RRTM_LW (Mlawer et al., 1997), uses the correlated-k method for LW radiative transfer, allowing calculation in 16 bands in the spectral range of 3.08-1000 $\mu \mathrm{m}$. The SW module, RRTM_SW (Mlawer and Clough, 1997), has 14 bands in the spectral range of $0.2-12.2 \mu \mathrm{m}$. In this study both SW and LW RRTM are configured to use the Discrete Ordinates Radiative Transfer (DISORT) solver with the 16 stream setup to perform radiative transfer calculations. Key RRTM features important for this study are detailed as follows.

1. k-distributions are obtained directly from a line-by-line radiative transfer model.

2. Modeled molecular absorbers are water vapor, carbon dioxide, ozone, methane and oxygen; additional sources of extinction are Rayleigh scattering in SW and nitrous oxide, nitrogen and halocarbons in LW. Aerosol scattering effects are taken into account in both SW and LW.

3. RRTM_SW error with respect to line-by-line calculations is $1 \mathrm{~W} \mathrm{~m}^{-2}$ for direct and $2 \mathrm{~W} \mathrm{~m}^{-2}$ for diffuse irradiance, respectively (Mlawer and Clough, 1997).

4. RRTM_LW error with respect to line-by-line calculations is $1.5 \mathrm{~W} \mathrm{~m}^{-2}$ (Mlawer et al., 1997).

\subsection{Atmospheric meteorological characteristics and chemical composition}

The meteorological characteristics required to drive RRTM were taken from the ECMWF reanalysis (ERA-Interim) data set. ERA-Interim data were obtained from the ECMWF Data Server with 0.125 by $0.125^{\circ}$ horizontal and $6 \mathrm{~h}$ temporal resolution. Necessary values were linearly interpolated in time. Gas components were prescribed as monthly climatology derived from the Global Modeling Initiative (GMI) model monthly mean output. The GMI 3-D chemistry and transport model was integrated with meteorological fields from the Modern Era Retrospective-analysis for Research and Applications (MERRA) and includes full chemistry for both the troposphere and stratosphere (Strahan et al., 2011; Douglass et al., 1999). All calculations were performed on the internal grid consisting of 37 vertical pressure levels. To avoid additional interpolation errors, boundaries were set up at constant
ERA-Interim pressure levels. Corresponding heights were calculated from geopotential. All additional necessary variables were interpolated on this internal pressure grid.

\subsection{Aerosols}

The aerosol optical properties in shortwave (extinction $\epsilon(\lambda)$, single scattering albedo $\omega(\lambda)$ and phase function $p(\lambda))$ are calculated for a given size distribution $N(r)$ (van de Hulst, 1957), assuming a mixture of randomly orientated spheroids, following the approach of Dubovik et al. (2006). In longwave, non-spherical effects are expected to be small (Haywood et al., 2005) and the analytic Mie solution (Veihelmann et al., 2006) is used. We assume that aerosol size distribution can be approximated by two log-normal modes (fine and coarse) with parameters $r_{i}$ and $\sigma_{i}$ (modal radius and standard deviation of the radius for number distribution, respectively):

$\frac{\mathrm{d} N(r)}{\mathrm{d} r}=\sum_{i=\mathrm{c}, \mathrm{f}} \frac{N_{i}}{r \sigma_{i} \sqrt{2 \pi}} e^{-\frac{\left(\ln (r)-\ln \left(r_{i}\right)\right)^{2}}{2 \sigma_{i}^{2}}}$,

where index $i$ goes for coarse (c) and fine (f) modes, $N_{i}$ is a total number density of particles of a given mode and $r$ is a radius.

Particles from the coarse and fine modes might have different refractive indices. We assume that aerosol is represented by one dominant type (dust, justified further). We assume that two modes are externally mixed, thus optical properties of the mixture could be obtained according to e.g., D'Almeida et al. (1991):

$\epsilon_{m}(\lambda)=\sum_{i=\mathrm{c}, \mathrm{f}} \epsilon_{i}(\lambda)$

$\omega_{m}(\lambda)=\frac{\sum_{i=\mathrm{c}, \mathrm{f}} \omega_{i}(\lambda) \epsilon_{i}(\lambda)}{\sum_{i=\mathrm{c}, \mathrm{f}} \epsilon_{i}(\lambda)}$

$p_{\mathrm{m}}(\lambda)=\frac{\sum_{i=\mathrm{c}, \mathrm{f}} p_{i}(\lambda) \omega_{i}(\lambda) \epsilon_{i}(\lambda)}{\sum_{i=\mathrm{c}, \mathrm{f}} \omega_{i}(\lambda) \epsilon_{i}(\lambda)}$,

where subscript " $m$ " means mix aerosol and $p_{i}(\lambda), \omega_{i}(\lambda)$ and $\epsilon_{i}(\lambda)$ are calculated for each mode separately.

To define aerosol size distribution, we use effective radius and standard deviation of the fine and coarse modes from Aeronet inversion products (Dubovik and King, 2000). For a given mode, effective radius is related to the modal radius $r_{i}$ in the following way (Lacis and Mishchenko, 1995):

$r_{\text {eff }}=\frac{\int_{0}^{\infty} r^{3} \frac{\mathrm{d} N_{i}(r)}{\mathrm{d} \ln (r)} \mathrm{d} \ln (r)}{\int_{0}^{\infty} r^{2} \frac{\mathrm{d} N_{i}(r)}{\mathrm{d} \ln (r)} \mathrm{d} \ln (r)}=r_{i} e^{\frac{5 \sigma_{i}^{2}}{2}}$. 
Aeronet provides column integrated values of AOD and, in order to define a plausible aerosol vertical profile, we collected Cloud-Aerosol Lidar and Infrared Pathfinder Satellite Observations (CALIPSO, Vaughan et al., 2004) scans in the region bounded by $32^{\circ} \mathrm{N}, 32^{\circ} \mathrm{E}$ and $10^{\circ} \mathrm{N}, 61^{\circ} \mathrm{E}$. This area covers the Arabian Peninsula, the Red Sea and the Arabian Gulf. Basic screening was applied to the CALIPSO Lidar Level 2 aerosol profile product, spanning the 20072013 time range. The CALIPSO extinction profiles at $532 \mathrm{~nm}$ were screened over land, averaged and combined into column AOD bins with 0.01 step shown in Fig. 1. In this figure, column AOD (horizontal axis) spans from fair-weather $(\mathrm{AOD}<1)$ to dust storm $(\mathrm{AOD}>2.5)$ conditions. Even though the number of observations drops significantly as AOD grows, we believe that during the dust storm, both fine and coarse modes are well-mixed within the boundary layer. Figure 1 shows a fast decrease of extinction of the aerosol layer at about $5 \mathrm{~km}$ at the top of the planetary boundary layer (PBL) for the entire range of column AODs. This behavior is consistent with measurements done during the SAMUM I campaign in southern Morocco in 2006 (Weinzierl et al., 2009), where observed well-mixed aerosol layers were restricted by capping inversion. On this basis, assumption about vertical profile were made and, in numerical experiments, aerosols from both modes were distributed uniformly between surface and $550 \mathrm{hPa}$. This simple vertical distribution was also used for fair-weather conditions. According to Liao and Seinfeld (1998), errors associated with uncertainty in the vertical profile have negligible impact in SW and are less than $1 \mathrm{~W} \mathrm{~m}^{-2}$ in LW for about 0.1 AOD between considered profiles.

According to CALIPSO, the ratio of the "not dust" and "dust" successful retrievals (screened) in the column between 0 and $5 \mathrm{~km}$ is 2.04 percent. Hence, not surprisingly, dust is a dominant aerosol type over the Arabian Peninsula and therefore in calculations we accounted only for dust. We used Balkanski et al. (2007) refractive indices (RIs) of the mineral dust internally mixed with $0.9,1.5$ and $2.7 \%$ volumeweighted hematite to calculate aerosol optical properties (referred to as B09, B15 and B27, respectively). Optical depths at $500 \mathrm{~nm}$ for each mode provided by the Aeronet spectral deconvolution algorithm (SDA) were used to derive the total number of particles $N_{i}$ in Eq. (1) to match the observed optical depth.

\subsection{Surface optical properties}

It is known that surface albedo is extremely important for calculation of the dust radiative effect (Houghton et al., 2001), as it defines bottom boundary conditions for the radiation transfer in the atmospheric column. For each wavelength it is calculated as a ratio of the reflected and incident surface radiation fluxes. However, surface albedo depends on several parameters and atmospheric conditions. Experimental and theoretical studies have shown its dependence on the solar
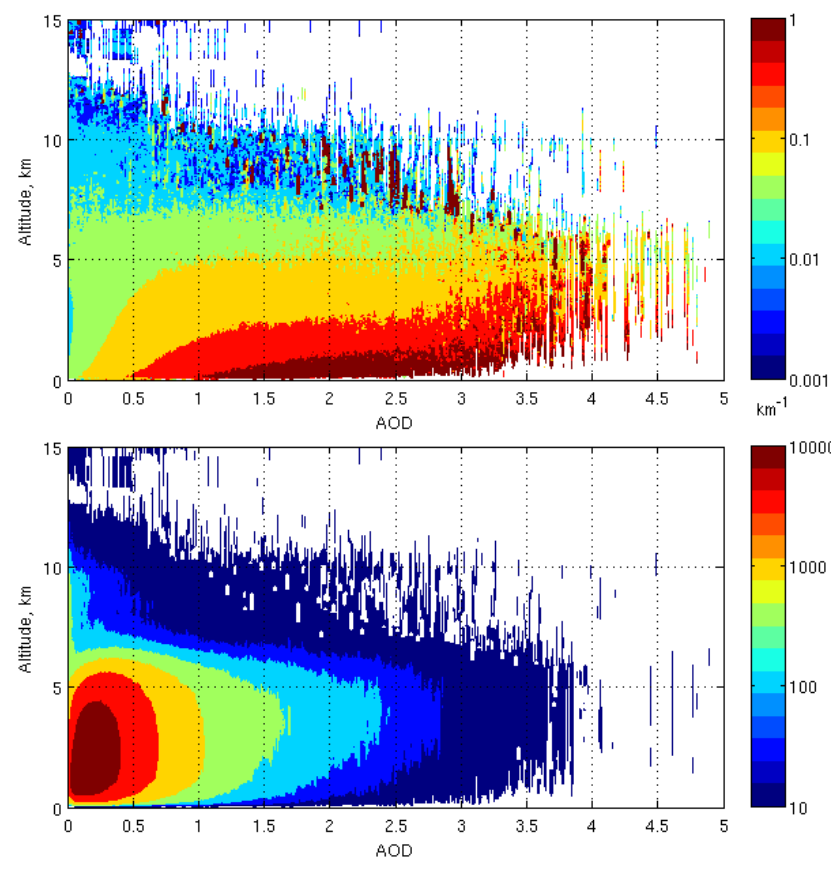

Figure 1. Extinction profile of the dust at $532 \mathrm{~nm}$ (top panel) and corresponding number of samples (bottom panel) as a function of column AOD, derived from CALIPSO Lidar Level 2 aerosol profile product. Extinction profiles were screened over the Arabian Peninsula (land) and combined into column AOD bins with 0.01 step. Values, averaged within each bin, are color-coded using the log scale.

zenith angle, ratio of the direct and diffuse fluxes and, in case of ocean surface, on wind speed (or surface roughness) and chlorophyll concentration (Lyapustin, 1999; Li et al., 2006; Jin et al., 2004). In this section we discuss both land and ocean surface albedo.

The Moderate Resolution Imaging Spectroradiometer (MODIS) instrument aboard Terra and Aqua satellites views the entire Earth's surface every 1 to 2 days, acquiring data in 36 spectral bands. The MODIS multidate and multiangular remotely sensed surface reflectances are used to derive MODIS Bidirectional Reflectance Distribution Function (BRDF)/Albedo product MCD43 based on the Rossthick-Li-sparse reciprocal model (Shuai et al., 2008). The MCD43A1 product provides the parameters associated with this model sufficient to compute the black-sky ( $q_{\text {bsa }}$, direct radiation) and white-sky ( $q_{\mathrm{wsa}}$, diffuse radiation) albedos. Thus, in SW, total albedo $q$ can be obtained as a weighted sum:

$q(\lambda, \theta)=\frac{q_{\mathrm{bsa}}(\lambda, \theta) F^{\mathrm{dir}}+q_{\mathrm{wsa}}(\lambda) F^{\mathrm{dif}}}{F^{\mathrm{dir}}+F^{\mathrm{dif}}}$,

where $\lambda$ is a wavelength, $\theta$ is a solar zenith angle, $F^{\mathrm{dir}}$ and $F^{\text {dif }}$ are the direct and diffuse fluxes, respectively.

For ocean surface we adopted parameterization provided by Jin et al. (2004). In this case, SW total spectral albedo is 
a weighted sum of four components:

$q(\lambda, \theta, w, \mathrm{chl})$

$=\frac{F^{\mathrm{dir}}\left(q_{\mathrm{s}}^{\mathrm{dir}}(\lambda, \theta, w)+q_{\mathrm{w}}^{\mathrm{dir}}(\lambda, \theta, w, \mathrm{chl})\right)+F^{\mathrm{dif}}\left(q_{\mathrm{s}}^{\mathrm{dif}}(\lambda, w)+q_{\mathrm{w}}^{\operatorname{dif}}(\lambda, w, \mathrm{chl})\right)}{F^{\mathrm{dir}}+F^{\mathrm{dif}}}$,

where $w$ is a wind speed, chl is a chlorophyll concentration, $q_{\mathrm{s}}^{\mathrm{dir}}, q_{\mathrm{s}}^{\mathrm{dif}}, q_{\mathrm{w}}^{\mathrm{dir}}$ and $q_{\mathrm{w}}^{\text {dif }}$ are surface direct and diffuse albedos and ocean volume direct and diffuse albedos, respectively. The effect of ocean foams (white caps) is also taken into account. Jin et al. (2004) show that their parameterization is in excellent quantitative and qualitative agreement with observations and correctly captures diurnal variations of the OSA.

LW surface emissivity is mostly defined by the surface type. Over land it also depends on the season and vegetation and is thus best observed from space. Daily land surface emissivities in LW were obtained by combining MODIS level 3 MOD11C1 and MYD11C1 products. LW emissivity for seawater was obtained from the Aster Spectral Library (Baldridge et al., 2009).

This formulation of the surface albedo (both for land and ocean) introduces nonlinearity in the radiation transfer calculations, since surface albedo itself depends on $F^{\mathrm{dir}}$ and $F^{\mathrm{dif}}$. Therefore, when calculating radiation transfer in a given atmospheric column, an iterative approach was used to obtain the ratio $r=\frac{F^{\text {dif }}}{F^{\mathrm{dir}}}$ (Li et al., 2006). During each iteration a new value of $r$ is obtained and is used in the next step. The iterations continue until the convergence criterion $\left|r_{i+1}-r_{i}\right|<35 \times 10^{-4}$ is satisfied, where $i$ is the iteration number. The convergence criterion is chosen so that the overall accuracy of the RRTM calculations is not diminished. In order to facilitate the convergence, an initial guess value of $r$ is chosen depending on the column optical depth.

\section{Radiation closure}

Observations over the Arabian Peninsula are scarce. Below we discuss the set of measurements that we were able to retrieve and employ in our study.

\subsection{Ground observations}

From 1995 until 2003, the King Abdulaziz City for Science and Technology (KACST) and the National Renewable Energy Laboratory (NREL) cooperated to establish a 12-station network of high-quality radiation monitoring installations across the Kingdom of Saudi Arabia. The Solar Village site served as the network operations center, calibration facility, and data retrieval and quality assessment center. One- and five-minute data are collected by a suite of instruments compatible with the BSRN specifications, including upwelling and downwelling longwave and shortwave fluxes (Al-Abbadi et al., 2002).

In the scope of collaboration with the WHOI (Woods Hole Oceanographic Institution), a fully instrumented shore-side tower was deployed at the KAUST campus in 2009 (Farrar et al., 2009) that routinely measures hourly average downward radiation fluxes (data are available at: http://uop.whoi. edu/projects/KAUST/, last access: 17 January 2015).

\subsection{TOA observations}

To test the simulated radiation fluxes at TOA we used satellite observations. Instantaneous footprint-level $(20 \mathrm{~km}$ nominal spatial resolution) observed fluxes and cloud coverage were obtained from Clouds and the Earth's Radiant Energy System (CERES, Wielicki et al., 1996) Single Scanner Footprint TOA/Surface Fluxes and Clouds (SSF) Level 2 Edition $3 \mathrm{~A}$ product. Pixels from Aqua and Terra within $0.2^{\circ}$ distance were collected for comparison. These data were obtained from the NASA Langley Research Center Atmospheric Science Data Center. Additionally, we made use of the Geostationary Earth Radiation Budget high-resolution (GERB HR) product (available from 2004 onward) which provides continuous observations of the TOA outgoing fluxes available every $15 \mathrm{~min}$ and which we re-gridded to $0.25^{\circ}$ spatial resolution (Harries et al., 2005; Dewitte et al., 2008). We also made a detailed comparison with the retrievals of SW and LW radiative forcing derived from GERB measurements, which are described in detail by Ansell et al. (2014) and investigated further by Banks et al. (2014). To empirically derive DRF one has to define the "pristine-sky" fluxes as a reference characteristic. In the SW, pristine-sky surface albedo is derived from a regression of measured planetary albedo against SEVIRI AOD (Brindley and Russell, 2009) within a $0.25^{\circ}$ grid cell. The SW dust radiative effect is then calculated by multiplying this pristine-sky albedo by the incoming downwelling SW flux, and subtracting the measured TOA flux. Meanwhile in the LW, the pristine-sky TOA LW flux is derived for each time slot using a 28 -day rolling reference window which also seeks to account for variations in atmospheric humidity and surface temperature (Brindley, 2007). As with the SW, the measured TOA LW flux is then subtracted from this pristinesky LW flux.

\section{Results}

In this section we discuss clear-sky radiative transfer calculations conducted for different locations over the Arabian Peninsula and the sensitivity studies. In each case mineral dust DRF is calculated as a difference between perturbed $(\mathrm{P})$ and control $(\mathrm{C})$ experiments, where $\mathrm{P}$ experiments account for dust aerosol and $\mathrm{C}$ experiments do not. Both $\mathrm{C}$ and $\mathrm{P}$ experiment calculations are carried out using the same meteorology and atmospheric composition. 
Table 1. Deviations from the default setup of the experiments conducted for the Solar Village case.

\begin{tabular}{ll}
\hline Experiment & Description \\
\hline $\mathrm{P}$ and C & approximated surface temperature \\
$\mathrm{PE}$ and CE & ERA-Interim surface temperature \\
PA and CA & $\begin{array}{l}\text { approximated surface temperature, } \\
\text { aerosol scattering is ignored in LW }\end{array}$ \\
\hline
\end{tabular}

\subsection{Radiation closure test and DRF}

In this section we conduct calculations for two specific locations: in the central Arabian desert at Solar Village and in the semi-desert area at the coastal plain of KAUST campus.

The first case study focuses on the 9-12 August 2002 DRF during fair-weather AOD conditions, based on Aeronet measurements at the Solar Village site established in 1999. For this case measurements of both the surface incident and reflected shortwave fluxes are available. They were used to estimate broadband surface albedo and compare it with the one derived from the model runs based on the MODIS BRDF/Albedo product. Description of the experiments and corresponding abbreviations are provided in Table 1 . The first set of perturbed and control experiments (denoted as $\mathrm{P}$ and $C$, respectively) uses surface temperature approximated from observations of the surface upwelling LW fluxes and the Stefan-Bolzmann law. The second set of experiments (denoted as PE and CE) follows a default setup (Sect. 2.2) and is based on surface temperature derived from the ERA-Interim product. The third set of experiments (denoted as PA and CA) is identical to the first set, but does not model LW scattering and uses absorption optical depth instead of extinction optical depth to exclude scattering effects.

The second case study deals with a major dust outbreak that occurred over the Arabian Peninsula during March 2012. The storm was observed by Aeronet at the KAUST campus site established in February 2012. The storm front first arrived on 18 March, causing strong AOD growth up to $\tau(0.5 \mu \mathrm{m}) \sim 1$.6. Maximum value $\tau(0.5 \mu \mathrm{m}) \sim 4.75$ was reached on 19 March 2012. During the next 5 days AOD gradually relaxed from $\tau(0.5 \mu \mathrm{m}) \sim 2$ to $\tau(0.5 \mu \mathrm{m}) \sim 0.5$. Since calculations in this section are based on Aeronet observations, simulations are only performed during the daytime at the exact time of each measurement.

Fluxes from satellite retrieval products, ground-based observations and the model used in this study span different spectral ranges as summarized in Table 2. The broadband fluxes are integrated over wavelengths and are not very sensitive to the exact position of the band's interfaces, as the interfaces are chosen to be in the regions of small intensities of the solar and terrestrial radiation (van de Hulst, 1957). However, cut off at 50 microns in LW may introduce positive
Table 2. Spectral ranges of the satellite products, ground observations and RRTM model. Wavelengths are given in microns.

\begin{tabular}{cccccc}
\hline & CERES & GERB & KAUST & Solar Village & RRTM \\
\hline SW & $0-5$ & $0.3-4$ & $0.28-2.8$ & $0.28-2.8$ & $0.2-12$ \\
LW & $5-100$ & $4-100$ & $3.5-50$ & $3.5-50$ & $3-1000$ \\
\hline
\end{tabular}

bias up to about $14 \mathrm{~W} \mathrm{~m}^{-2}$ when RRTM fluxes are compared to ground-based observations.

In order to quantitatively compare time series of computed and observed quantities $\left(y^{\mathrm{c}}\right.$ and $\left.y^{\mathrm{o}}\right)$ we define the absolute error (root-mean-square error, RMSE) given by

$\operatorname{RMSE}=\sqrt{\frac{\sum_{i} e_{i}^{2}}{N}}$

where $N$ is the number of elements in the time series, deviation at a given time $e_{i}=y_{i}^{\mathrm{c}}-y_{i}^{\mathrm{o}}$. Similarly, relative error $\left(\mathrm{RMSE}_{\mathrm{r}}\right)$ is given by

$\mathrm{RMSE}_{\mathrm{r}}=\frac{\mathrm{RMSE}}{\sqrt{\left.\frac{\sum_{i}}{(} y_{i}^{\mathrm{c}}\right)^{2}} N} 100 \%$.

\subsubsection{Solar Village}

This case study is characterized by naturally cloud-free conditions and relatively low column AOD shown in Fig. 2. We were able to achieve good agreement with the SW downwelling surface direct fluxes shown in Fig. 2. While the instrument uncertainty is $2 \%$ at $1 \mathrm{~kW} \mathrm{~m}^{-2}$, RMSE does not exceed $10 \mathrm{~W} \mathrm{~m}^{-2}$ and $\mathrm{RMSE}_{\mathrm{r}}$ is only $1.9 \%$, as aerosol extinction optical depth provided by Aeronet is fairly accurate. At the same time, we have stronger forward scattering in calculations than in observations as indicated by the positively biased diffuse flux (RMSE is $36 \mathrm{~W} \mathrm{~m}^{-2}$ and RMSE $\mathrm{r}$ is $20 \%$ ). As a result, total albedo $q$ (Eq. 6) shifts more towards the $q_{\text {wsa. }}$. Nevertheless, taking into account that diffuse flux in the perturbed experiment is on average 3.5 times bigger than in the control (not shown here), this bias has minor impact on effective albedo (Eq. 6). The abrupt "triangular-like" shape of the computed LW fluxes is due to linear interpolation of the $6 \mathrm{~h}$ meteorological data. In LW, RMSE reaches $17 \mathrm{~W} \mathrm{~m}^{-2}$, given the instrument uncertainty of $\pm 10 \mathrm{~W} \mathrm{~m}^{-2}$ and $\mathrm{RMSE}_{\mathrm{r}}$ is $4.2 \%$. Bias due to difference in the RRTM and instrument spectral range contributes up $14 \mathrm{~W} \mathrm{~m}^{-2}$ to the error and discrepancies in meteorological profiles have only minor impact.

Figure 3 shows diurnal variations of the broadband surface albedo derived from BSRN measurements and calculated in the perturbed experiment. Since observations are attributed to a point location and the numerical experiment is based on the MODIS BRDF product attributed to a $500 \mathrm{~m}$ pixel, exact quantitative comparison with measurements is somewhat 

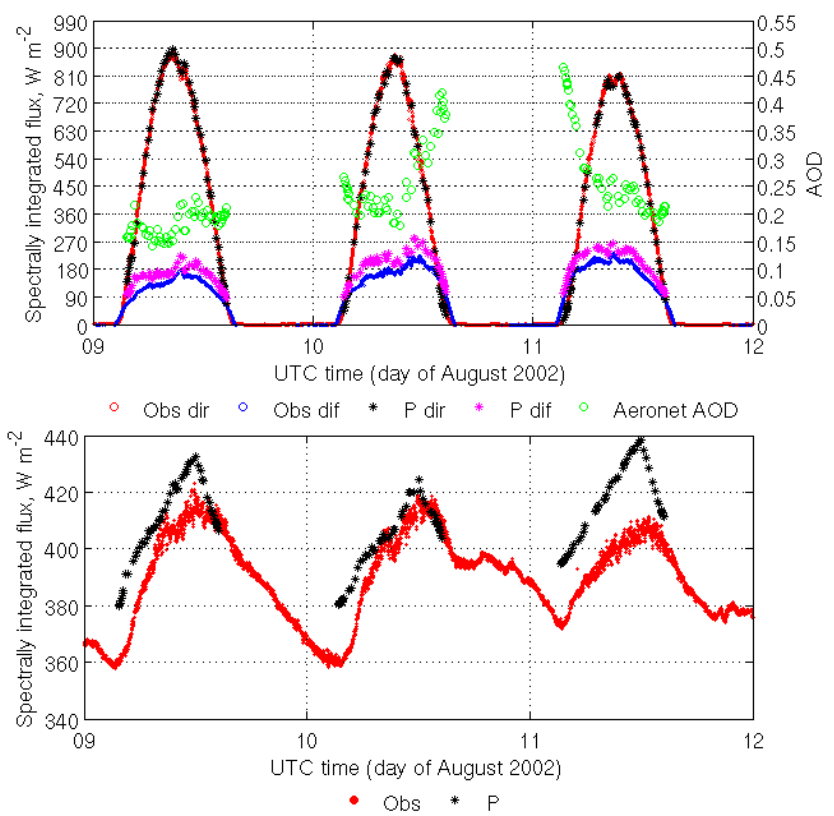

Figure 2. Surface downwelling fluxes at Solar Village. The top panel presents SW surface downwelling perturbed experiment direct (P dir, black stars) and diffuse (P dif, purple stars), in situ measured direct (Obs dir, red circles) and diffuse (Obs dif, blue circles) fluxes and Aeronet SDA column AOD at $500 \mathrm{~nm}$ (green, right vertical axis). The bottom panel presents LW surface downwelling perturbed experiment ( $\mathrm{P}$, black stars) and in situ measured (Obs, red circles) fluxes.

hindered. Nevertheless, MODIS BRDF parameters are adequate and qualitatively capture a strong diurnal cycle of the surface albedo up to solar zenith angles of about $75^{\circ}$.

Due to positive bias in the surface downwelling flux (mostly due to diffuse components, Fig. 2) and in the surface albedo (Fig. 3), computed surface upwelling SW fluxes shown in Fig. 4 are slightly bigger than observed and RMSE reaches $19 \mathrm{~W} \mathrm{~m}^{-2}$; $\mathrm{RMSE}_{\mathrm{r}}$ is $8.4 \%$, given $3 \%$ instrument uncertainty at $1 \mathrm{~kW} \mathrm{~m}^{-2}$. Surface upwelling LW fluxes in the perturbed experiment agree with observations by construction. At the same time, error in ERA-Interim surface temperature increases RMSE to $25 \mathrm{~W} \mathrm{~m}^{-2}$ and $\mathrm{RMSE}_{\mathrm{r}}$ to $4.5 \%$ for the PE experiment relative to measurements.

Figure 5 shows that computed SW TOA outgoing fluxes are also consistent with CERES-inferred values (RMSE is $20 \mathrm{~W} \mathrm{~m}^{-2}$ and $\mathrm{RMSE}_{\mathrm{r}}$ is $6.3 \%$ ). In LW, due to corrected surface temperature, $\mathrm{P}$ experiment has slightly better agreement with observations than PE experiment (RMSE is $18 \mathrm{~W} \mathrm{~m}^{-2}$ and $20 \mathrm{Wm}^{-2}, \mathrm{RMSE}_{\mathrm{r}}$ is 1.7 and $1.9 \%$, respectively). This can be compared to the estimates of the CERES instantaneous TOA flux error, which are based on a series of consistency tests and are discussed in Loeb et al. (2003). For example, all-sky TOA flux uncertainties for Terra in tropics are estimated to be $14.3 \mathrm{~W} \mathrm{~m}^{-2}(5.1 \%)$ and $5.1 \mathrm{~W} \mathrm{~m}^{-2}(1.8 \%)$ in $\mathrm{SW}$ and $\mathrm{LW}$, respectively (according

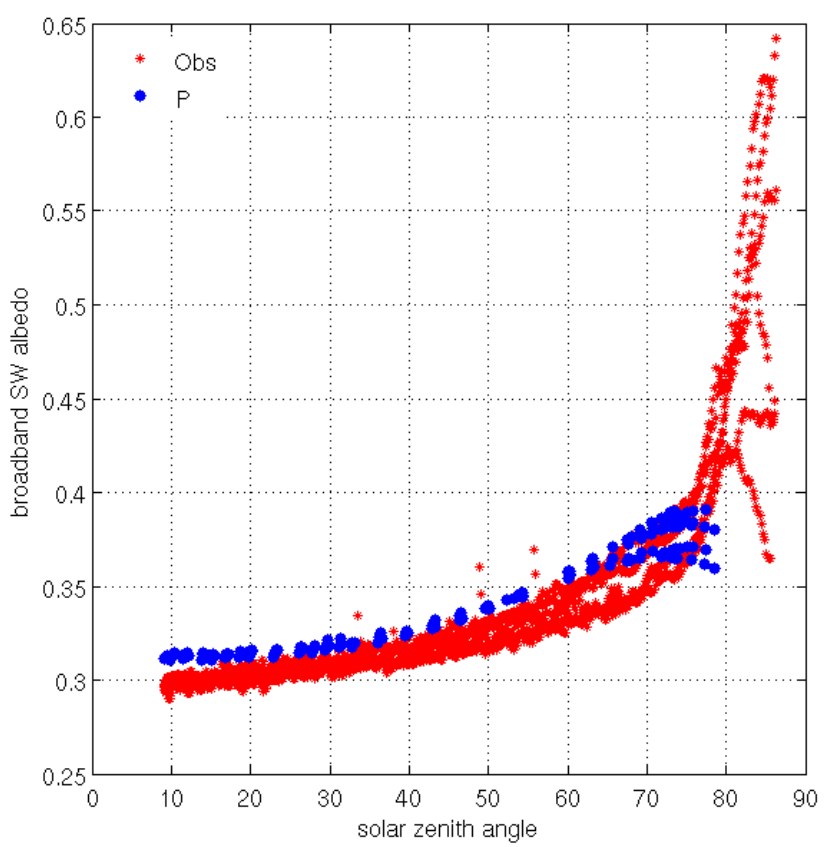

Figure 3. Three days accumulated broadband SW albedo at Solar Village derived from ground-based measurements (Obs, red stars) and perturbed experiment based on MODIS BRDF (P, blue circles).

to CERES Terra Edition3A SSF Data Quality Summary, available at: https://eosweb.larc.nasa.gov/project/ceres/ quality_summaries/CER_SSF_Terra_Edition3A.pdf, last access: 17 January 2015). Comparison of the TOA fluxes completes the radiation closure.

Given a good agreement (with uncertainties close to instrumental) of the surface (downwelling and upwelling) and TOA (upwelling) fluxes and thus fairly accurate radiation closure, we focus on calculating the mineral dust radiative forcings. We first define total downward minus upward flux as

$F=F_{\downarrow}-F_{\uparrow}$,

where $F_{\downarrow}$ and $F_{\uparrow}$ are the downward and upward fluxes, respectively. Thus, following the convention, the instantaneous forcing $\Delta F$ (either TOA or BOA) is defined as the difference of total downward minus upward fluxes in the $\mathrm{P}$ and $\mathrm{C}$ experiments:

$\Delta F=F^{\mathrm{P}}-F^{\mathrm{C}}$

and atmospheric absorption $\Delta F^{\mathrm{A}}$ due to dust aerosol is then defined as the difference between TOA and BOA forcings:

$\Delta F^{\mathrm{A}}=\Delta F^{\mathrm{TOA}}-\Delta F^{\mathrm{BOA}}$.

The positive value of the radiative forcing $\Delta F^{\mathrm{TOA}}, \Delta F^{\mathrm{BOA}}$, $\Delta F^{\mathrm{A}}$ means heating of the atmospheric column, underlying surface or atmosphere, respectively. 

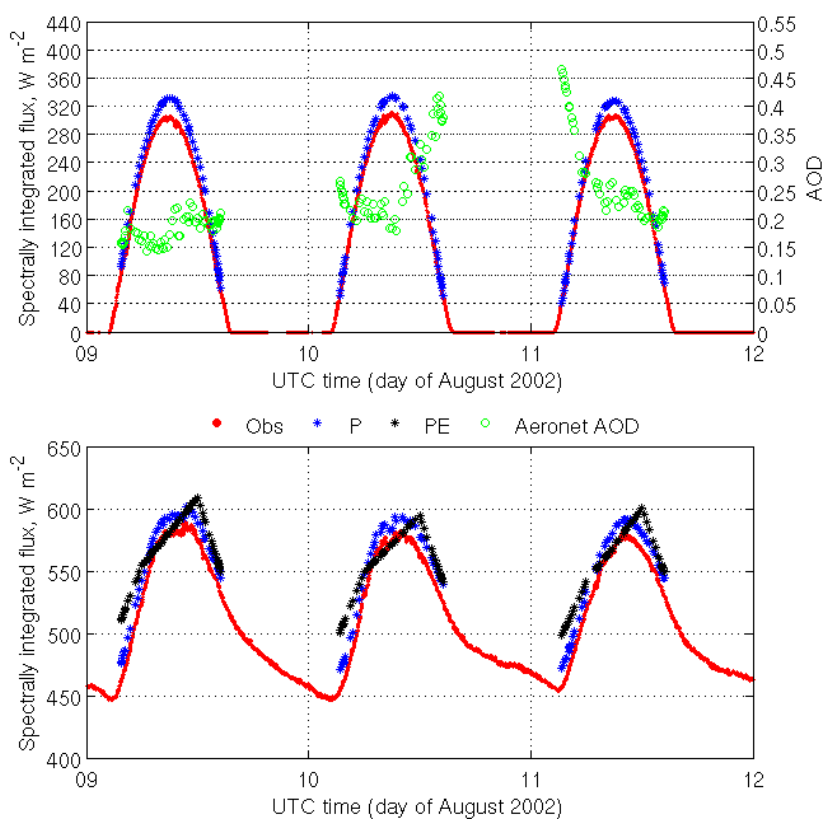

Figure 4. SW (top panel) and LW (bottom panel) computed surface upwelling fluxes with approximated surface temperature (P, blue) and prescribed from ERA-Interim (PE, black) and in situ measurements (Obs, red) at Solar Village. Aeronet SDA column AOD at $500 \mathrm{~nm}$ (top panel, green) is plotted against the right vertical axis.
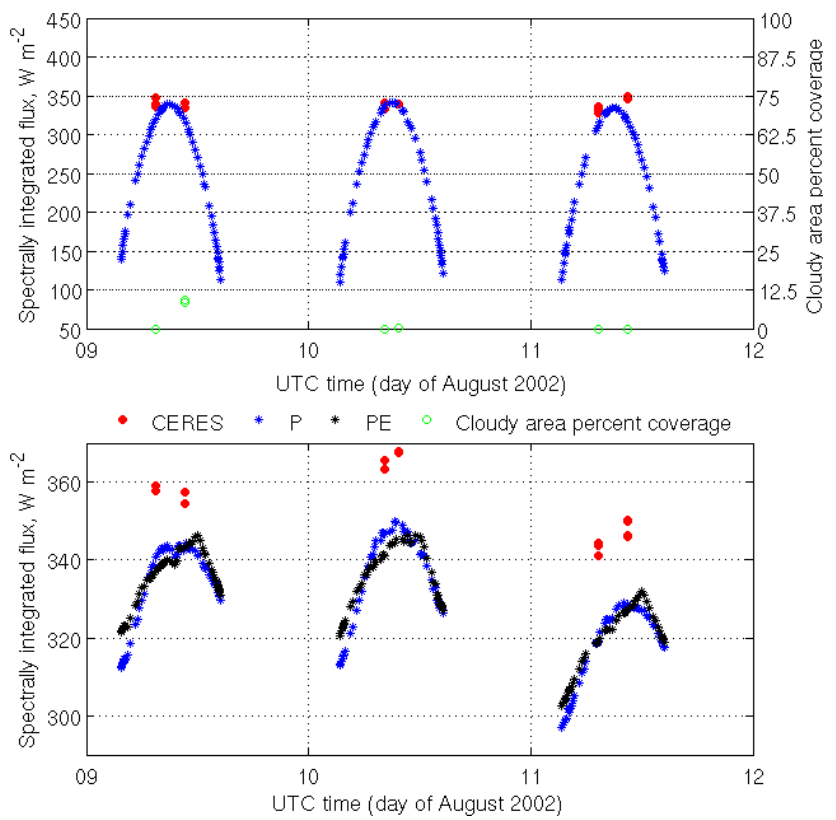

Figure 5. TOA upwelling fluxes at Solar Village. The top (SW) and bottom (LW) panels present fluxes computed with approximated surface temperature $(\mathrm{P}$, blue) and prescribed from ERA-Interim (PE, cyan) and satellite-inferred fluxes (CERES, red). Cloudy area percent coverage derived from CERES product (top panel, green) is plotted against the right vertical axis.
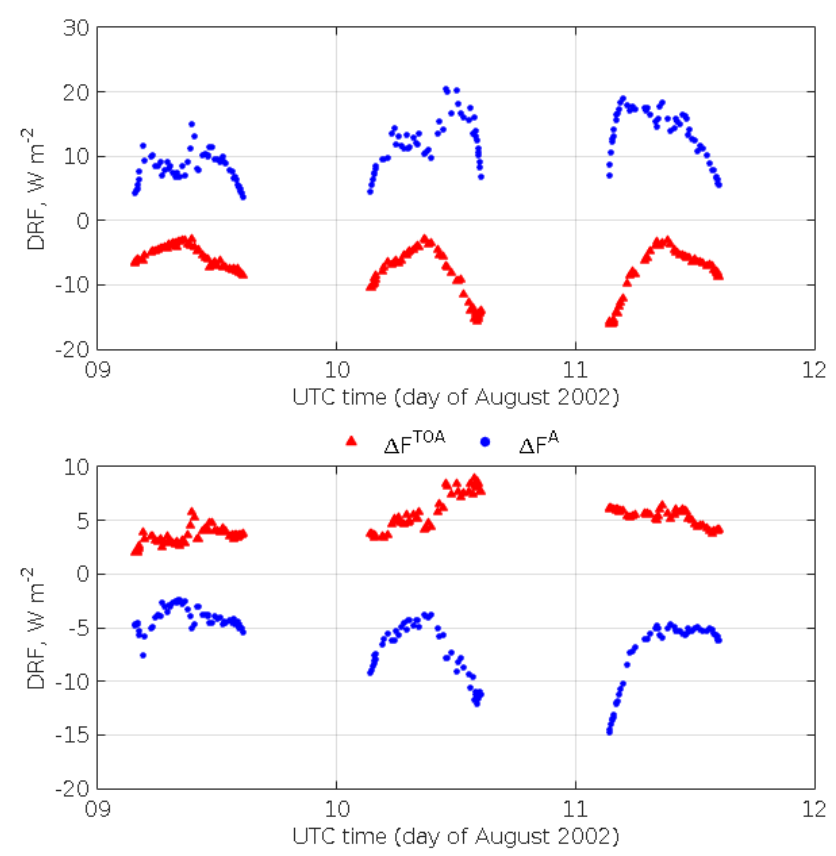

Figure 6. SW (top panel) and LW (bottom panel) $\Delta F^{\mathrm{TOA}}$ (red triangles) and atmospheric absorption $\Delta F^{\mathrm{A}}$ (blue circles) computed for the experiments set with approximated surface temperature at Solar Village.

Figure 6 shows that $\Delta F^{\mathrm{TOA}}$ and $\Delta F^{\mathrm{A}}$ have strong diurnal cycles. In SW, dust causes cooling of the atmospheric column (but $\Delta F^{\mathrm{TOA}}$ is close to zero during the local solar noon) and increases atmospheric absorption. In LW the effect is opposite, but has comparable magnitudes. Sensitivity of the LW DRF to the surface temperature (not shown) is much smaller compared to fluxes, as expected, and RMSE of the LW DRF is less than $0.5 \mathrm{~W} \mathrm{~m}^{-2}$ between $\mathrm{P}$ and $\mathrm{PE}$ experiments, given that the RMSE of the surface temperature is $2 \mathrm{~K}$. Liao and Seinfeld (1998) also considered dependence of the LW DRF on atmospheric conditions (including temperature and water vapor profiles) and reported similar values. LW scattering has a stronger impact on LW $\Delta F^{\mathrm{TOA}}$ than on $\Delta F^{\mathrm{A}}$ and RMSE is $2.9 \mathrm{~W} \mathrm{~m}^{-2}$ and $0.1 \mathrm{~W} \mathrm{~m}^{-2}$, respectively, between $\mathrm{P}$ and PA experiments. Similar results have been reported by Dufresne et al. (2002) and Sicard et al. (2014). The number of large particles in the size distribution might be potentially underestimated by Aeronet, and thus the impact of LW scattering could be underestimated. Errors associated with the surface albedo are discussed separately in Sect. 4.2.2.

\subsubsection{KAUST campus}

The time span of the numerical experiments for the KAUST case consists of several days of fair-weather AOD followed by the major dust outbreak that occurred over the Arabian Peninsula on 18-20 March 2012 and several days of recovery. Figure 7 shows the impact of this dust event on 

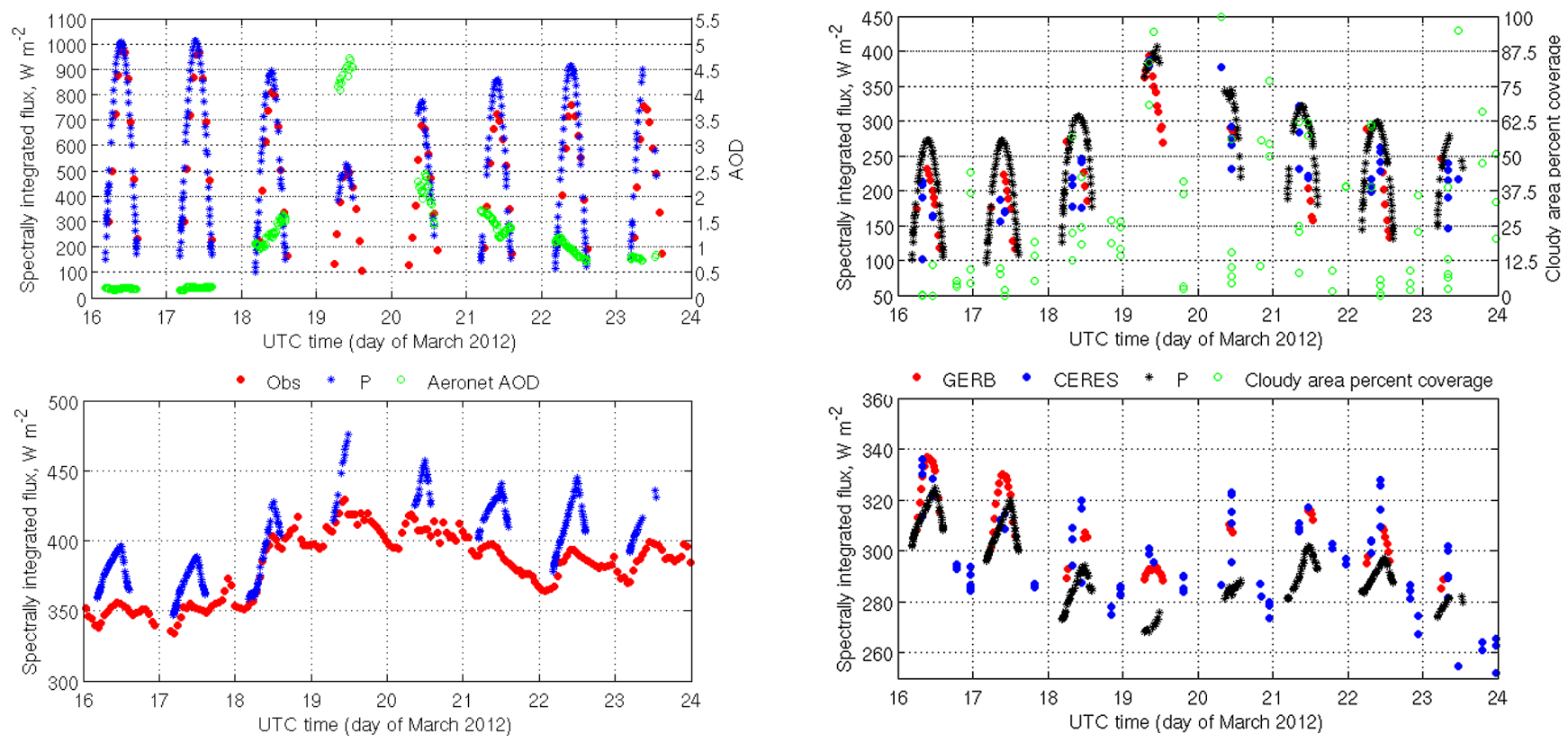

Figure 7. SW (top panel) and LW (bottom panel) surface downwelling fluxes at KAUST for the perturbed experiment (P, blue) and in situ measurements (Obs, red). Aeronet SDA column AOD at $500 \mathrm{~nm}$ (top panel, green) is plotted against the right vertical axis.

the surface downwelling fluxes. Peak AOD at KAUST was reached on 19 March. As a result, observed surface downwelling SW flux reduced to about $500 \mathrm{~W} \mathrm{~m}^{-2}$, which is half of the corresponding control experiment value. Due to high column AOD, direct flux almost disappeared and all the downwelling flux was represented by the diffuse component only. A similar effect was reported by Slingo et al. (2006) for the March 2006 dust storm at Niamey, Niger. SW surface cooling was partly compensated by increased downwelling LW flux from the dust layer.

Strong reflection of the SW radiation back to space was observed during the storm. The top panel in Fig. 8 shows that outgoing SW fluxes increased by about $150 \mathrm{~W} \mathrm{~m}^{-2}$, which is consistent with the satellite retrievals. Unlike the Solar Village case, clouds were present during the selected days as shown on the top panel of Fig. 8. This fact degrades the agreement and explains biases in the computed fluxes relative to observations since calculations are done for clear-sky conditions. Presence of clouds implies higher column optical depth than assumed in the model and thus observed SW downwelling fluxes are smaller than computed, which is consistent with the results shown on the top panel in Fig. 7.

For this case study, GERB cloud-screened SW and LW TOA DRF are available for comparison and are shown in Fig. 9. According to Ansell et al. (2014), estimated GERB DRF error both in SW and LW is $\pm 15 \mathrm{~W} \mathrm{~m}^{-2}$. Similar to the Solar Village case, TOA DRF exhibits strong diurnal cycle. SW DRF is strictly negative and reaches about

Figure 8. SW (top panel) and LW (bottom panel) perturbed experiment (P, black) and satellite-inferred (GERB, red and CERES, blue) TOA upwelling fluxes at KAUST. Cloudy area percent coverage derived from CERES product (top panel, green) is plotted against the right vertical axis.

$-150 \mathrm{~W} \mathrm{~m}^{-2}$ when AOD is at its highest. In LW mineral dust causes significant warming of the Earth-atmosphere system, reaching $50 \mathrm{~W} \mathrm{~m}^{-2}$. Unlike the Solar Village, the impact of $\mathrm{LW}$ scattering is critical in this case (RMSE is $6 \mathrm{Wm}^{-2}$ and $\mathrm{RMSE}_{\mathrm{r}}$ is $38 \%$ ) with maximum error on 19 March reaching $14 \mathrm{~W} \mathrm{~m}^{-2}$. Two independent sets of TOA forcings (model and GERB) agree fairly well in magnitude (RMSE is $24 \mathrm{~W} \mathrm{~m}^{-2}$ and $5 \mathrm{~W} \mathrm{~m}^{-2}$ in SW and LW, respectively) and general behavior, confirming that the model captures the main quantitative features of the process.

\subsection{Diurnal cycle of SW DRF}

In this section we focus on the sensitivity of the SW DRF diurnal cycle at the TOA and BOA and atmospheric absorption by aerosol, i.e., $\Delta F^{\mathrm{TOA}}, \Delta F^{\mathrm{BOA}}$ and $\Delta F^{\mathrm{A}}$, with respect to several parameters that span the range of values representative for the Arabian Peninsula. Specifically, we consider dependence on solar zenith angle $\theta$ and sensitivity to the total column AOD $\tau$, aerosol size distribution $\frac{\mathrm{d} N}{\mathrm{~d} r}$, aerosol refractive index RI and surface albedo $q$ :

$\Delta F=f\left(\theta, \tau, \frac{\mathrm{d} N}{\mathrm{~d} r}, \mathrm{RI}, q(\theta, r)\right)$.

While the middle Arabian Peninsula is extremely arid, coastal areas receive more precipitation, have more vegetation and are less reflective. The Red Sea reflects relatively little. To cover this range, we consider ocean, coastal plain 

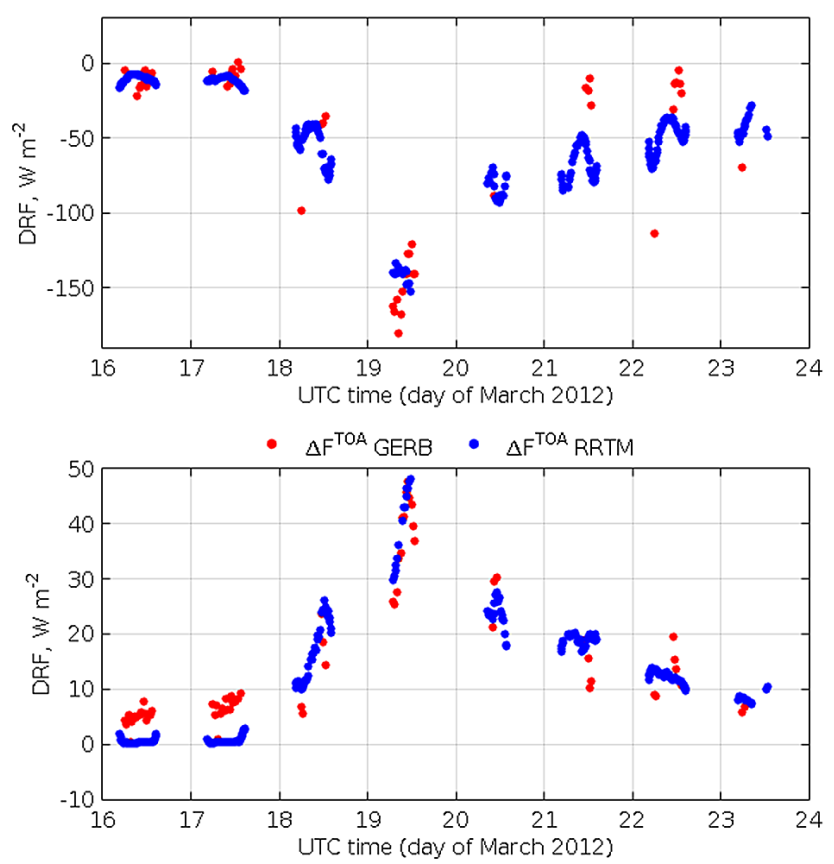

Figure 9. SW (top panel) and LW (bottom panel) TOA DRF at KAUST derived from the model (RRTM, blue) and satellite retrieval (GERB, red).

and desert surface albedos. The first two albedos are obtained from Solar Village and KAUST cases (see Sect. 4.1.1 and 4.1.2). The ocean surface albedo was parametrized (see Sect. 2.4) with fixed values of the wind speed $\left(w=5 \mathrm{~m} \mathrm{~s}^{-1}\right)$ and chlorophyll concentration $\left(\mathrm{chl}=0.15 \mathrm{mg} \mathrm{m}^{-3}\right)$. Three different RIs of the coarse mode (B09, B15, B27) are considered. Since fine mode is mostly represented by the clay particles that contain more hematite compared to the coarse mode, we only consider one fixed RI of the fine mode (B27). Numerical calculations are done with 10 min temporal resolution. Meteorology and gas composition profiles are based on the Solar Village location on 9 August 2002.

Unlike the Solar Village and KAUST case studies, in this section we conduct sensitivity analysis to model parameters rather than considering a specific time period. Size distribution statistics are derived from Aeronet Level 2.0 inversion product as a function of total column AOD over the Arabian Peninsula (Fig. 10). For fair-weather conditions, fine- and coarse-mode AOD are comparable to each other. For more severe events, coarse-mode AOD contribution dominates and scales as 5 to 1 relative to the fine mode. In terms of microphysical properties, scaling of the coarse-mode AOD is accompanied by the shift towards larger radii and narrowing of the size distribution. Fine-mode size distribution scaling is characterized by growth of their standard deviation $\sigma$. The same analysis for northern Africa shows similar scaling patterns of the aerosol size distribution and AOD.
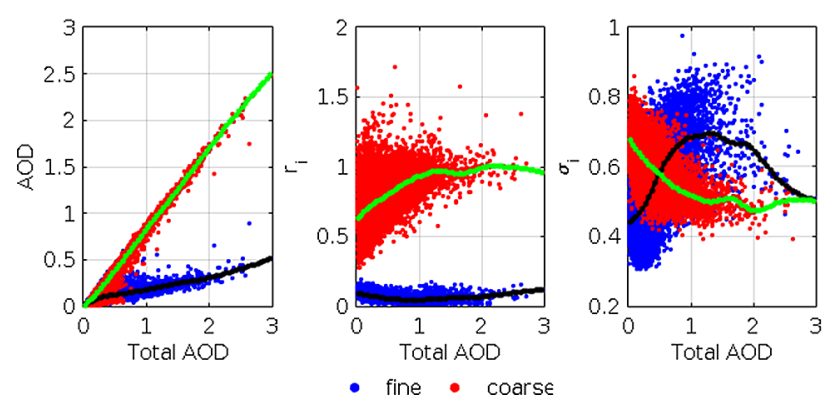

Figure 10. Fine- and course-mode AOD (blue and red, respectively, left panel) at $674 \mathrm{~nm}$, modal radius $r_{i}$ (middle panel) and standard deviation $\sigma_{i}$ (right panel) derived from Aeronet Inversion Level 2.0 product over the Arabian Peninsula. Thick lines indicate fitted values of the fine (black) and coarse (green) mode used in sensitivity calculations.
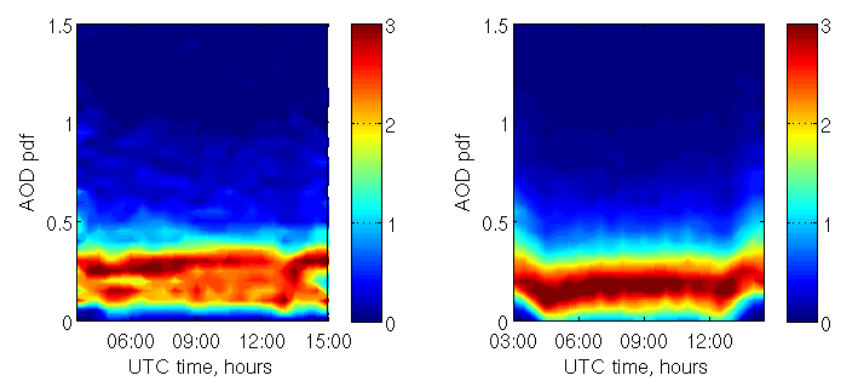

Figure 11. AOD at $674 \mathrm{~nm}$ pdf diurnal cycle derived from Aeronet AOT level 2.0 product at KAUST (left panel) and Solar Village (right panel). Data span is 2012-2014 at KAUST and 1999-2013 at Solar Village. Both locations are in the $+3 \mathrm{~h}$ time zone.

Obtained statistics were fitted as a function of total column AOD covering the range from 0 to 3 as shown in Fig. 10. These scaling regimes were used in Eq. (1) to build the aerosol size distribution and calculate optical properties of dust aerosol.

In order to estimate the diurnal cycle of AOD we use AOD statistics derived from Aeronet AOT Level 2.0 product. Figure 11 shows the diurnal cycle of the AOD probability density function (pdf) at KAUST and Solar Village. For each station, pdf was computed by collecting AOD observations into AOD bins with 0.05 stepping at $30 \mathrm{~min}$ intervals, which then were normalized so that the integral of the pdf from zero to positive infinity is equal to 1 in a particular time slot. Figure 11 shows that AOD diurnal cycle at both locations is rather uniform with relatively weak tendency for higher AOD values in the morning and late afternoon. Banks et al. (2014) also reported low variability of the daytime cycle in mean SEVIRI and Aeronet AOD over the Bordj Badji Mokhtar site in the central Sahara.

We discuss below the sensitivity of the TOA SW DRF diurnal cycle computed for different RIs, surface albedos and AODs. In Fig. 12 the simulated TOA forcing for the ocean 

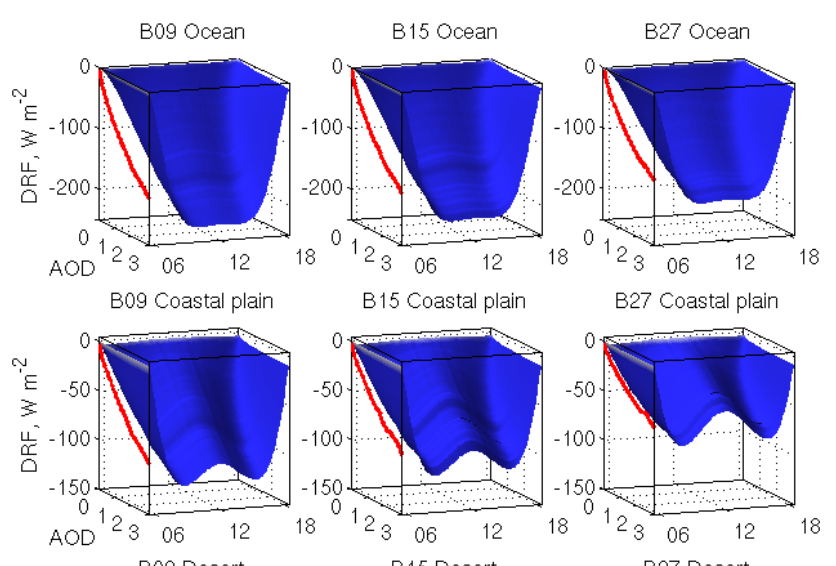

B15 Coastal plain

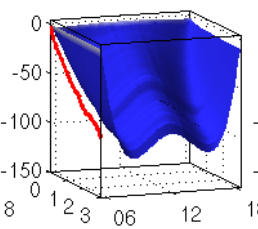

B27 Coastal plain

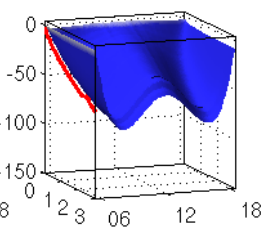

B15 Desert
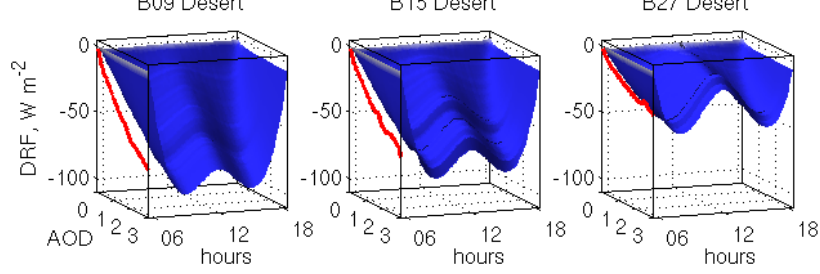

Figure 12. SW TOA DRF over ocean, coastal plain and desert surface albedo (top to bottom) for B09, B15 and B27 refractive indices (left to right) as a function of column AOD and local daytime (hours). Mean local daytime values (red) are projected on the DRFAOD plane.

case (top row) exhibits a relatively simple pattern with time of day, with maximal values of about $-200 \mathrm{~W} \mathrm{~m}^{-2}$ seen from 10 to $14 \mathrm{~h}$. The magnitude of this forcing gets weaker with enhanced aerosol absorption (left to right). As the surface gets more reflective (top to bottom), the forcing is weakened and goes from being relatively flat during local noon to exhibiting a symmetrical weakening around local noon. The contrast between peak forcing and this localized reductions (min-max-min structure, MMM) becomes more exacerbated with increased aerosol absorption and surface albedo, such that the maximum difference in forcing between morning/evening and local noon is seen for the most absorbing aerosol over the desert surface (bottom right panel). These results are consistent with those derived observationally by Ansell et al. (2014) and Banks et al. (2014) over northern Africa, where the sign of the forcing switches from negative to positive and then again to negative through the course of the day, indicating a SW cooling-heating-cooling of the Earth-atmosphere system. Additionally, Fig. 12 shows that daily mean TOA DRF is not a linear function of the total AOD (red line) and efficiency $\left(\frac{\Delta F^{\mathrm{TOA}}}{\tau}\right)$ of the daily mean forcing as a function total AOD declines faster over more reflective surfaces and for more absorbing aerosols.

\subsubsection{Process analysis}

SW TOA DRF shown in Fig. 12 has nontrivial shape and strong diurnal cycle. In order to qualitatively explain the

mechanisms responsible for forming this shape and understand the interplay of different factors, we consider a few special cases. We assume now that the surface albedo do not change during the daytime. We use the same experiment setups presented in Sect. 4.2 but manually override certain parameters and assume that total column AOD is equal to 0.5. To demonstrate dependence on the surface albedo we consider black surface ( $q=0$ for all wavelengths), desert (measured during the B300 flight over Mauritania; Johnson and Osborne, 2011) and white surface ( $q=1$ for all wavelengths) albedo. To demonstrate dependence on aerosol absorption and anisotropic scattering, we consider absorbing $(\omega=\omega *$, same as in Sect. 4.2) and non-absorbing ( $\omega=1$ for all wavelengths) dust, isotropic ( $g=0$ for all wavelengths, where $g$ is a asymmetry parameter) and anisotropic ( $g=g^{*}$, same as in Sect. 4.2) scattering by aerosol (see Fig. 13). This approach allows us to extract the impact of each parameter on the DRF diurnal cycle. Let us consider first black body surface albedo and non-absorbing dust (black curves in two left columns in Fig. 13). In this case surface does not reflect and TOA upward flux is only due to reflected radiation by the dust layer $\left(F_{\text {dust }}^{\text {reflected }}\right)$ and atmospheric Rayleigh scattering. Neglecting small changes in the atmospheric absorption, TOA DRF is almost equal to BOA DRF. $F_{\text {dust }}^{\text {refled }}$ does not depend on surface albedo. However, it does depend on the aerosol scattering phase function. Due to dust anisotropic scattering, TOA, and thus BOA DRF in this case, have diurnal variation with MMM structure, shown in the second column of Fig. 13. On the other hand, in the isotropic case $(g=0)$ both TOA and BOA DRF follow a simple diurnal cycle with one minimum at noon (left column in Fig. 13).

For the white body surface albedo case (blue curves), $\Delta F^{\mathrm{BOA}}$ is equal to zero. $\Delta F^{\mathrm{A}}$ equals $\Delta F^{\mathrm{TOA}}$ and both are small. Due to smaller surface reflected flux, for any intermediate albedo case (including the real-case desert albedo, red curves) $\Delta F^{\mathrm{TOA}}$ is bounded by the black and white body albedo cases and the diurnal variation persists. In all cases $\Delta F^{\mathrm{A}}$ is small. To conclude the discussion of the nonabsorbing aerosol case, we emphasize that both TOA and BOA DRF are strictly non-positive (if we neglect the small changes in atmospheric absorption) over any surface and MMM structures are due to anisotropic scattering by dust.

If we turn on the aerosol absorption (right two columns in Fig. 13) for the black surface albedo, $F_{\text {dust }}^{\text {reflected is slightly }}$ reduced compared to the non-absorbing aerosol case, since part of the photons are absorbed instead of being scattered. While TOA DRF remains almost the same and surface reflected flux is absent, there is an additional significant component $\Delta F^{\mathrm{A}}$, which causes stronger cooling of the surface. For positive values of $g$ (including physical range of $0.5-0.7$ ) forward scattering prevails and thus BOA is more sensitive to absorption than TOA DRF. This also implies that MMM structures tend to persist for TOA and flatten for BOA DRF (right column). 

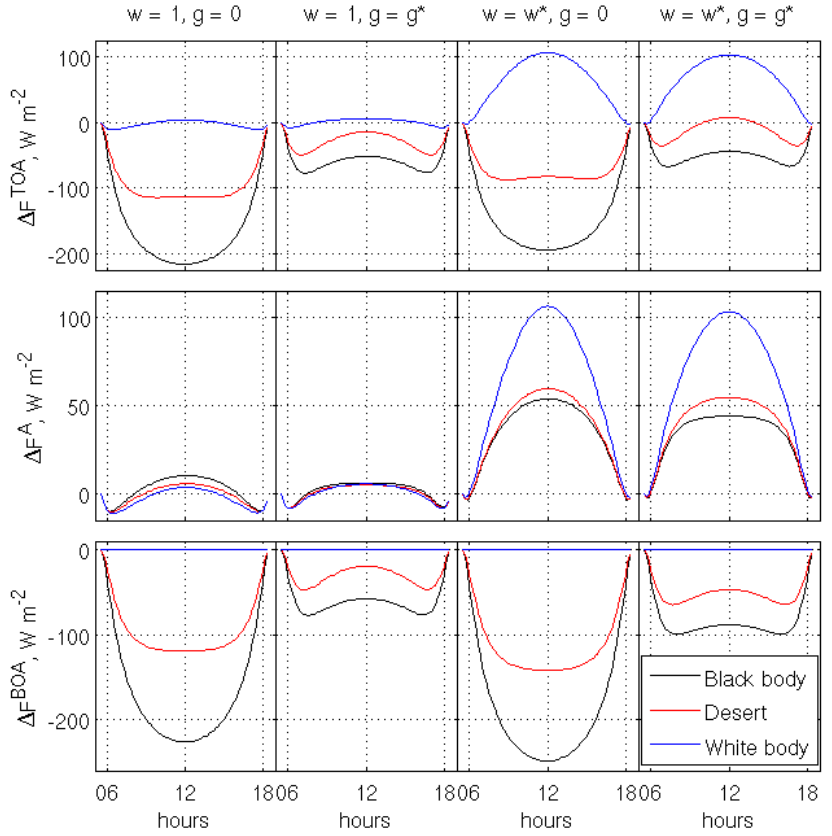

Figure 13. Special cases of the SW DRF diurnal cycle for the black surface (black), desert (red) and white surface (blue) surface albedos. $\Delta F^{\mathrm{TOA}}, \Delta F^{\mathrm{A}}$ and $\Delta F^{\mathrm{BOA}}$ (from top to bottom rows) are computed for the non-absorbing and absorbing (first two and last two columns respectively) and for the isotropic and anisotropic (first, third and second, fourth columns respectively) aerosol cases. Spectrally gray override values are provided in the titles, where $g^{*}$ and $\omega^{*}$ indicate that actual spectral values were used. Total column $\mathrm{AOD}$ at $674 \mathrm{~nm}$ is 0.5 .

For the white body albedo case, since the $\Delta F^{\mathrm{BOA}}$ is zero, $\Delta F^{\mathrm{TOA}}$ is equal to $\Delta F^{\mathrm{A}}$, where both quantities are strictly non-negative. Similar to the non-absorbing aerosol case, for any intermediate surface albedo, TOA DRF is bounded by the black and white surface albedo cases. Nevertheless, unlike the non-absorbing aerosol case, the upper bound is positive, which may lead to sign changes during the diurnal cycle. To conclude the discussion of the absorbing dust case, we emphasize the following.

1. Anisotropic scattering by dust significantly contributes to the diurnal cycle of the TOA and BOA DRF and explains the MMM structure.

2. Higher surface albedo modulates $\Delta F^{\mathrm{TOA}}, \Delta F^{\mathrm{BOA}}$ and $\Delta F^{\mathrm{A}}$ and shifts them towards the positive bound.

3. Stronger absorption by dust significantly contributes to the diurnal cycle of the $\Delta F^{\mathrm{A}}$. It also shifts $\Delta F^{\mathrm{TOA}}$ and $\Delta F^{\mathrm{A}}$ towards the positive bound but has the opposite effect on $\Delta F^{\mathrm{BOA}}$.

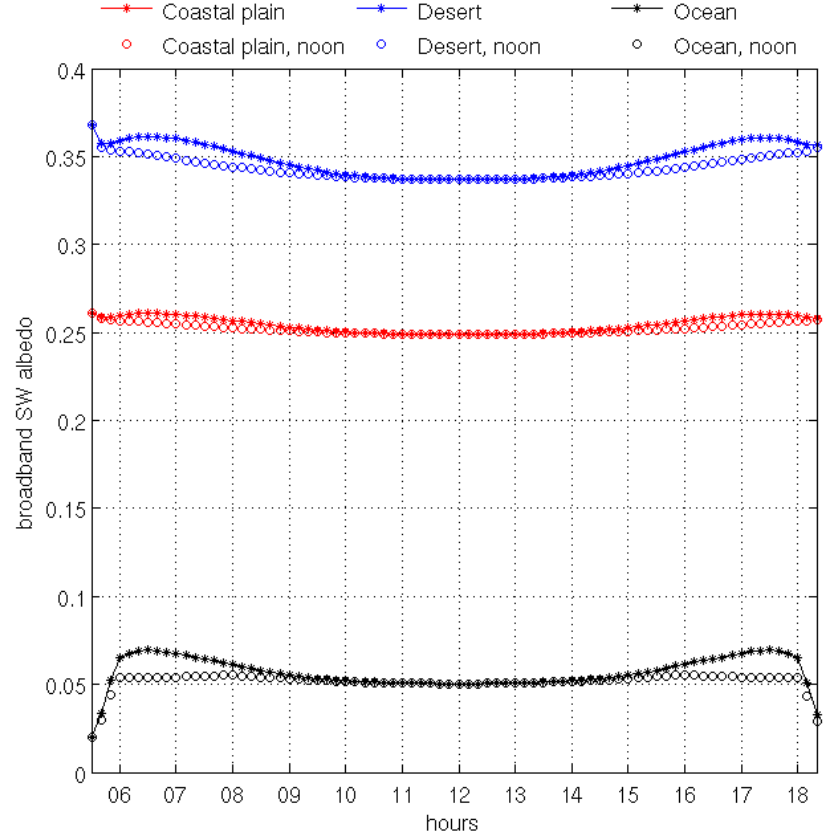

Figure 14. Broadband SW albedo for desert (blue), coastal plain (red) and ocean (black), with diurnal cycle (lines with stars) and fixed solar zenith angle (circles) averaged over the range of considered optical depths.

\subsubsection{Effect of the surface albedo}

In the previous section we considered SW DRF dependence on the parameters that do not have a diurnal cycle. In this section we quantify the effect of the albedo diurnal cycle on the SW TOA DRF. Airplane observations of the albedo usually are done at nadir. So, we define the reference albedo for the solar zenith angle at local noon, i.e.,

$q_{\text {fixed }}(r)=q\left(\theta_{\text {noon }}, r\right)$.

The difference $\delta F$ of the forcings calculated with the varying albedo $q$ and the fixed albedo $q_{\text {fixed }}$ is a function of the solar zenith angle, optical depth and albedo:

$\delta F=\Delta F(\theta, \tau, q(\theta, r))-\Delta F\left(\theta, \tau, q\left(\theta=\theta_{\text {noon }}, r\right)\right)$,

both at BOA and TOA. Figure 14 shows corresponding broadband albedo diurnal cycles at the desert, coastal plain and ocean obtained from our numerical experiments. Albedo in Fig. 14 is averaged over the range of optical depths (from 0 to 3 ) for a given refractive index (B15). During the local solar noon, $q$ and $q_{\text {fixed }}$ coincide exactly (by construction), but they deviate as the solar zenith angle grows. Changes in the $q_{\text {fixed }}$ are solely due to variations of diffuse-to-direct flux ratio $r$. Figure 15 shows corresponding contribution to the SW TOA DRF associated with diurnal cycle of $q$ compared to $q_{\text {fixed }}$. Since surfaces tend to be more reflective with increasing solar zenith angle, $\delta F$ is positive and causes a warming 

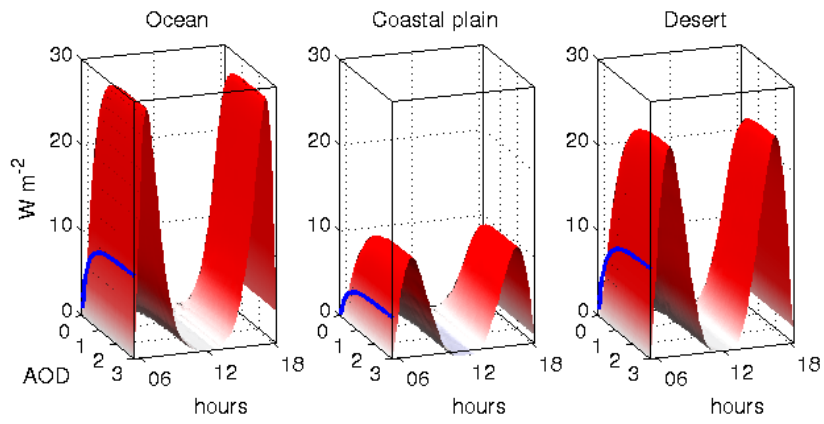

Figure 15. Contribution $\delta F$ of the albedo diurnal cycle to the TOA SW DRF over ocean, coastal plain and desert (left to right), assuming B15 refractive index as a function of column AOD and local daytime (hours). Mean local daytime values (blue) are projected on the DRF-AOD plane.

effect. The strongest effect is reached during the morning and evening hours and thus albedo diurnal cycle decreases the diurnal variability of the SW TOA DRF. The effect quickly saturates when AOD reaches 1. It is strongest over the ocean (up to $29 \mathrm{~W} \mathrm{~m}^{-2}$ ), weakens over the desert (up to $24 \mathrm{~W} \mathrm{~m}^{-2}$ ) and is smallest for the coastal plain (up to $11 \mathrm{~W} \mathrm{~m}^{-2}$ ).

\subsection{Daily DRF sensitivity}

In this section we focus on the daily mean dust DRF, discuss the contribution of the SW, LW and NET (SW plus LW) effects and their sensitivity to the surface albedo, and aerosol absorption efficiency. Similarly to Sect. 4.2.1, in calculations we use 0.5 as a reference column AOD at $674 \mathrm{~nm}$. Figure 16 shows daily mean $\Delta F^{\mathrm{TOA}}, \Delta F^{\mathrm{BOA}}$ and $\Delta F^{\mathrm{A}}$ for $\mathrm{B} 09, \mathrm{~B} 15$ and B27 RI and for the ocean, coastal plain and desert surface albedos. In this figure, surface albedo grows from left to right columns and inside each column aerosol absorption also grows from left to right. For all RIs and surface albedos, dust causes the SW cooling of the atmospheric column (negative TOA DRF) and of the surface (negative BOA DRF) and increases atmospheric absorption (positive $\Delta F^{\mathrm{A}}$ ). In LW the sign of the forcings is opposite. In LW aerosol warms both the surface and the entire atmospheric column, but cools the atmosphere itself. Reduced variability of the LW DRF compared to SW DRF is a consequence of much smaller changes of the aerosol absorption and surface albedo or emissivity in LW than in SW. At BOA the LW forcing is weaker than SW forcing. At TOA, SW cooling dominates LW warming of the atmospheric column and for the strongly absorbing B27 case over the desert, the NET forcing weakens to almost zero. NET atmospheric absorption changes the sign between $\mathrm{B} 15$ and $\mathrm{B} 27$ refractive indices from negative to positive. Figure 16 also shows that SW BOA DRF is more sensitive to increasing absorption by dust than SW TOA DRF, as was discussed in Sect. 4.2.1.
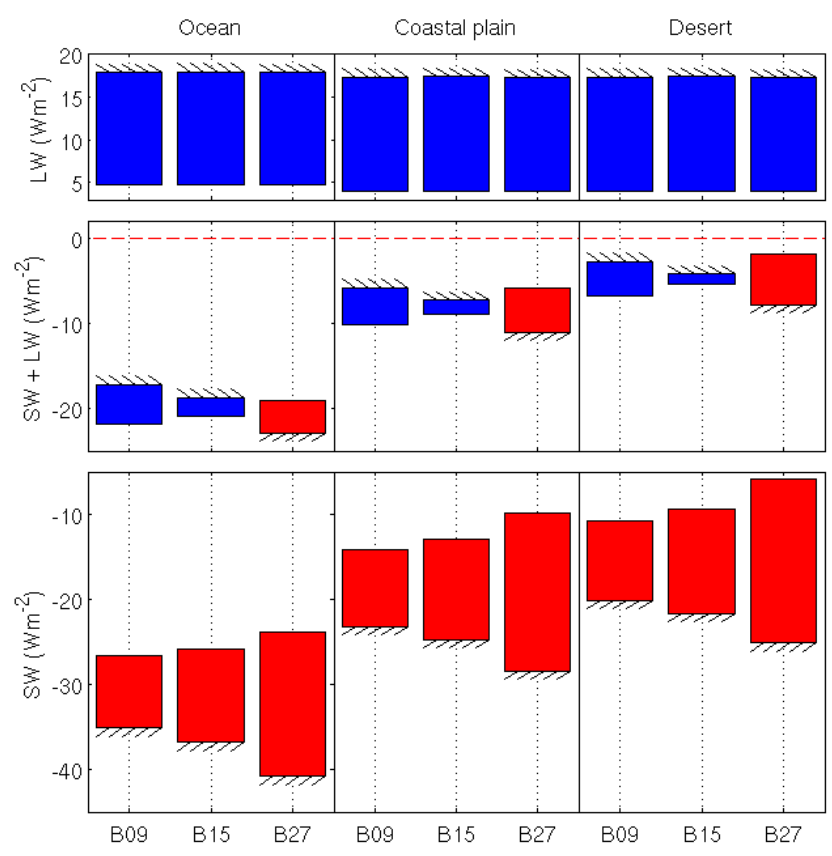

Figure 16. Daily mean dust DRF for B09, B15 and B27 RI (indicated by the vertical dash line in each column) and ocean, coastal plain and desert (left to right) surface albedo over the Arabian Peninsula. Each bar represents three diagnostic variables: $\Delta F^{\mathrm{TOA}}$, $\Delta F^{\mathrm{BOA}}$ and $\Delta F^{\mathrm{A}}$. Hatching indicates the $\Delta F^{\mathrm{BOA}}$ edge and thus the opposite edge is $\Delta F^{\mathrm{TOA}}$. The height of the bar corresponds to the absolute value of the atmospheric absorption due to dust or $\left|\Delta F^{\mathrm{A}}\right|$ and color indicates the sign of the $\Delta F^{\mathrm{A}}$ (blue for negative or cooling, red for positive or warming). LW, SW values and their sum are shown in the top, bottom and middle rows, respectively. Total column AOD used in calculations is 0.5 at $674 \mathrm{~nm}$.

\section{Conclusions}

A column radiation transfer model was used to investigate dust instantaneous direct radiative forcing over the Arabian Peninsula for a range of optical depths covering fair-weather and dust storm conditions. According to the CALIPSO product, dust is a dominant aerosol in this area. We calculated the forcing of the dust aerosol over ocean, coastal plain and desert surfaces, accounting for non-sphericity of dust aerosol and using a range of plausible refractive indices suggested by Balkanski et al. (2007) and we were able to achieve good agreement of the surface and TOA fluxes with in situ measurements and satellite retrievals. Available measurements of surface reflected SW radiation were used to estimate the broadband surface albedo and test computed surface upwelling fluxes based on the MODIS BRDF products. Even though MODIS product and in situ measurements are attributed to different spatial scales, analysis showed that in simulations surface albedo diurnal cycle was well-captured, both quantitatively and qualitatively. Our calculations for Solar Village fair-weather conditions revealed strong diurnal cycle of TOA DRF. Dust aerosol cools the entire column in 
SW throughout the diurnal cycle. However, during the local solar noon the forcing weakens. The daily mean SW DRF for the considered realistic range of aerosol parameters and surface albedos remains negative. A similar result was reported by Osborne et al. (2011) for the comparable AOD during June 2007 over land areas between Mauritania and Niger. The KAUST campus case during the dust storm conditions is characterized by a stronger cooling of atmospheric column due to lower surface albedo. Distinct diurnal cycle of the TOA DRFs is also present.

Compiling aerosol statistics using Aeronet data, we found similar scaling patterns between the Arabian Peninsula and North Africa. In particular, coarse- and fine-mode AODs at $674 \mathrm{~nm}$ on an average scale as 5 to 1 . Thus, similar to the measurements in Sahara during the ACE-2 campaign 1997 of Otto et al. (2007), coarse mode has a prevailing contribution to the total optical properties of the dust aerosol over the Arabian Peninsula. We found that SW TOA DRF, as a function of the solar zenith angle, has three distinctive extrema structures. The forcing remains strictly negative over the ocean surface for the entire day. The diurnal variations are more prominent over the more reflective surfaces and, for the strongly absorbing B27 case, dust aerosol forcing weakens to almost zero over the desert during the local solar noon.

We found that for typical conditions over the Arabian Peninsula, the relative difference in daily mean SW fluxes is about $0.5-1.5 \%$ in experiments where dust aerosol is treated as a mixture of randomly oriented spheroids and as a mixture of spheres. Process analysis for black and white surface albedo, non-absorbing dust and isotropic scattering revealed that dust anisotropic scattering controls the diurnal variability of the SW BOA and TOA DRF. This emphasizes the importance of the assumptions about particle shape and thus the phase function to correctly capture the maximum and minimum of the SW TOA DRF diurnal cycle. Due to prevailing forward scattering by dust aerosol, BOA DRF is more sensitive to changes in single scattering albedo or absorption by dust, than TOA DRF. This also implies, that diurnal variations of the TOA DRF are less sensitive to changes in atmospheric absorption by dust than BOA DRF.

Daily mean dust DRF over the Arabian Peninsula for a $0.5 \mathrm{AOD}$ at $674 \mathrm{~nm}$ showed that in all considered cases, dust causes cooling of the atmospheric column, while over the desert surface albedo and B27 refractive index case, the forcing is almost zero. For all considered surface albedo types, net atmospheric absorption due to dust changes the sign between B15 and B27 refractive indices.

Several sources of the dust forcing uncertainty are currently known, which include refractive index, number size distribution and surface albedo. The treatment of the surface albedo is often oversimplified and albedo itself is assumed to be fixed. We found that intrinsic variability of the surface albedo and its dependence on the atmospheric conditions are important factors to be taken into account, especially for the desert surfaces, where daily mean TOA DRF is close to zero.
The main results could be formulated as follows.

- Dust is a major aerosol over the Arabian Peninsula and its coarse mode mostly contributes to the total column AOD compared to fine mode.

- The developed model allows relatively accurate radiation closure to be carried out.

- The calculated fluxes are in a good agreement with best available observations.

- Dust DRF is estimated and compares well to the independently derived satellite values.

- Dust TOA DRF has strong diurnal cycle over desert, but three extrema structures are present over any surface.

- Anisotropic scattering by dust significantly contributes to the diurnal cycle of the SW TOA and BOA DRF.

- Diurnal intrinsic variability of the surface albedo has a strong impact on the dust DRF diurnal cycle.

Acknowledgements. We thank the PI Naif Al-Abbadi for his effort in establishing and maintaining the Solar Village Aeronet site, David Doelling for his expertise in CERES products, Susan Strahan for providing gas composition of the atmosphere, Tom Farrar for establishing the meteorological tower at KAUST, Alexei Lyapustin for the thoughtful discussions about the MODIS land products and surface albedo, Oleg Dubovik for sharing the software package for calculating the optical properties of the spheroids and the Supercomputing Laboratory for computer time at King Abdullah University of Science and Technology (KAUST) in Thuwal, Saudi Arabia. Research reported in this publication was supported by KAUST. Helen Brindley and Jamie Banks are supported by KAUST CRG-1-2012-STE-IMP grant.

Edited by: M. Dameris

\section{References}

Al-Abbadi, N., Alawaji, S., Bin Mahfoodh, M., Myers, D., Wilcox, S., and Anderberg, M.: Saudi Arabian solar radiation network operation data collection and quality assessment, Renew. Energ., 25, 219-234, 2002.

Ansell, C., Brindley, H. E., Pradhan, Y., and Saunders, R.: Mineral dust aerosol net direct radiative effect during GERBILS field campaign period derived from SEVIRI and GERB, J. Geophys. Res.-Atmos., 119, 4070-4086, 2014.

Baldridge, A., Hook, S., Grove, C., and Rivera, G.: The ASTER spectral library version 2.0, Remote Sens. Environ., 113, 711715, 2009.

Balkanski, Y., Schulz, M., Claquin, T., and Guibert, S.: Reevaluation of Mineral aerosol radiative forcings suggests a better agreement with satellite and AERONET data, Atmos. Chem. Phys., 7, 81-95, doi:10.5194/acp-7-81-2007, 2007. 
Bangalath, H. K. and Stenchikov, G.: Role of dust direct radiative effect on the tropical rain belt over Middle East and North Africa: A high-resolution AGCM study, J. Geophys. Res.-Atmos., 120, 4564-4584, doi:10.1002/2015JD023122, 2015.

Banks, J. R., Brindley, H. E., Hobby, M., and Marsham, J. H.: The daytime cycle in dust aerosol direct radiative effects observed in the central Sahara during the Fennec campaign in June 2011, J. Geophys. Res.-Atmos., 119, 13861-13876, doi:10.1002/2014JD022077, 2014.

Basart, S., Pérez, C., Cuevas, E., Baldasano, J. M., and Gobbi, G. P.: Aerosol characterization in Northern Africa, Northeastern Atlantic, Mediterranean Basin and Middle East from direct-sun AERONET observations, Atmos. Chem. Phys., 9, 8265-8282, doi:10.5194/acp-9-8265-2009, 2009.

Brindley, H.: Estimating the top-of-atmosphere longwave radiative forcing due to Saharan dust from satellite observations over a west African surface site, Atmos. Sci. Lett., 8, 74-79, 2007.

Brindley, H. E. and Russell, J. E.: An assessment of Saharan dust loading and the corresponding cloud-free longwave direct radiative effect from geostationary satellite observations, J. Geophys. Res.-Atmos., 114, d23201, doi:10.1029/2008JD011635, 2009.

Cavazos-Guerra, C. and Todd, M. C.: Model Simulations of Complex Dust Emissions over the Sahara during the West African Monsoon Onset, Adv. Meteorol., 2012, 351731, doi:10.1155/2012/351731, 2012.

Claquin, T., Schulz, M., Balkanski, Y., and Boucher, O.: Uncertainties in assessing radiative forcing by mineral dust, Tellus B, 50, ISSN 1600-0889, doi:10.1034/j.1600-0889.1998.t01-2-00007.x, 2011

Cuesta, J., Marsham, J. H., Parker, D. J., and Flamant, C.: Dynamical mechanisms controlling the vertical redistribution of dust and the thermodynamic structure of the West Saharan atmospheric boundary layer during summer, Atmos. Sci. Lett., 10, 34-42, 2009

D'Almeida, G. A., Koepke, P., and Shettle, E. P.: Atmospheric aerosols: global climatology and radiative characteristics, A. Deepak Pub. Hampton, 1991.

Derbyshire, E.: Natural minerogenic dust and human health, AMBIO: A Journal of the Human Environment, 36, 73-77, 2007.

Dewitte, S., Gonzalez, L., Clerbaux, N., Ipe, A., Bertrand, C., and De Paepe, B.: The geostationary earth radiation budget edition 1 data processing algorithms, Adv. Space Res., 41, 1906-1913, 2008

Douglass, A., Prather, M., Hall, T., Strahan, S., Rasch, P., Sparling, L., Coy, L., and Rodriguez, J.: Choosing meteorological input for the global modeling initiative assessment of high-speed aircraft, J. Geophys. Res.-Atmos., 104, 27545-27564, 1999.

Dubovik, O. and King, M. D.: A flexible inversion algorithm for retrieval of aerosol optical properties from Sun and sky radiance measurements, J. Geophys. Res.-Atmos., 105, 20673-20696, 2000.

Dubovik, O., Sinyuk, A., Lapyonok, T., Holben, B. N., Mishchenko, M., Yang, P., Eck, T. F., Volten, H., Muñoz, O., Veihelmann, B., van der Zande, W. J., Leon, J.-F., Sorokin, M., and Slutsker, I.: Application of spheroid models to account for aerosol particle nonsphericity in remote sensing of desert dust, J. Geophys. Res.Atmos., 111, d11208, doi:10.1029/2005JD006619, 2006.
Dufresne, J.-L., Gautier, C., Ricchiazzi, P., and Fouquart, Y.: Longwave scattering effects of mineral aerosols, J. Atmos. Sci., 59, 1959-1966, 2002.

Farrar, J., Lentz, S., Churchill, J., Bouchard, P., Smith, J., Kemp, J., Lord, J., Allsup, G., and Hosom, D.: King Abdullah University of Science and Technology (KAUST) mooring deployment cruise and fieldwork report, Technical report, Woods Hole Oceanographic Institution, WHOI-KAUST-CTR-2009, 2, 2009.

Giles, D. M., Holben, B. N., Eck, T. F., Sinyuk, A., Smirnov, A., Slutsker, I., Dickerson, R. R., Thompson, A. M., and Schafer, J. S.: An analysis of AERONET aerosol absorption properties and classifications representative of aerosol source regions, J. Geophys. Res.-Atmos., 117, d17203, doi:10.1029/2012JD018127, 2012.

Ginoux, P., Prospero, J. M., Gill, T. E., Hsu, N. C., and Zhao, M.: Global-scale attribution of anthropogenic and natural dust sources and their emission rates based on MODIS Deep Blue aerosol products, Rev. Geophys., 50, rG3005, doi:10.1029/2012RG000388, 2012.

Harries, J. E., Russell, J. E., Hanafin, J. A., Brindley, H., Futyan, J., Rufus, J., Kellock, S., Matthews, G., Wrigley, R., Last, A., Mueller, J., Mossavati, R., Ashmall, J., Sawyer, E., Parker, D., Caldwell, M., Allan, P. M., Smith, A., Bates, M. J., Coan, B., Stewart, B. C., Lepine, D. R., Cornwall, L. A., Corney, D. R., Ricketts, M. J., Drummond, D., Smart, D., Cutler, R., Dewitte, S., Clerbaux, N., Gonzalez, L., Ipe, A., Bertrand, C., Joukoff, A., Crommelynck, D., Nelms, N., Llewellyn-Jones, D. T., Butcher, G., Smith, G. L., Szewczyk, Z. P., Mlynczak, P. E., Slingo, A., Allan, R. P., and Ringer, M. A.: The Geostationary Earth Radiation Budget Project, B. Am. Meteorol. Soc., 86, 945-960, doi:10.1175/BAMS-86-7-945, 2005.

Haywood, J. M., Allan, R. P., Culverwell, I., Slingo, T., Milton, S., Edwards, J., and Clerbaux, N.: Can desert dust explain the outgoing longwave radiation anomaly over the Sahara during July 2003?, J. Geophys. Res.-Atmos., 110, d05105, doi:10.1029/2004JD005232, 2005.

Houghton, J. T., Ding, Y., Griggs, D. J., Noguer, M., van der Linden, P. J., Dai, X., Maskell, K., and Johnson, C.: Climate change 2001: the scientific basis, vol. 881, Cambridge university press, Cambridge, 2001.

Jin, Z., Charlock, T. P., Smith, W. L., and Rutledge, K.: A parameterization of ocean surface albedo, Geophys. Res. Lett., 31, 122301, doi:10.1029/2004GL021180, 2004.

Johnson, B. and Osborne, S.: Physical and optical properties of mineral dust aerosol measured by aircraft during the GERBILS campaign, Q. J. Roy. Meteorol. Soc., 137, 1117-1130, 2011.

Kinne, S., Lohmann, U., Feichter, J., Schulz, M., Timmreck, C., Ghan, S., Easter, R., Chin, M., Ginoux, P., Takemura, T., Tegen, I., Koch, D., Herzog, M., Penner, J., Pitari, G., Holben, B., Eck, T., Smirnov, A., Dubovik, O., Slutsker, I., Tanre, D., Torres, O., Mishchenko, M., Geogdzhayev, I., Chu, D. A., and Kaufman, Y.: Monthly averages of aerosol properties: A global comparison among models, satellite data, and AERONET ground data, $\mathrm{J}$ Geophys. Res.-Atmos., 108, 4634, doi:10.1029/2001JD001253, 2003.

Koffi, B., Schulz, M., Bréon, F.-M., Griesfeller, J., Winker, D., Balkanski, Y., Bauer, S., Berntsen, T., Chin, M., Collins, W. D., Dentener, F., Diehl, T., Easter, R., Ghan, S., Ginoux, P., Gong, S., Horowitz, L. W., Iversen, T., Kirkevåg, A., Koch, 
D., Krol, M., Myhre, G., Stier, P., and Takemura, T.: Application of the CALIOP layer product to evaluate the vertical distribution of aerosols estimated by global models: AeroCom phase I results, J. Geophys. Res.-Atmos., 117, d10201, doi:10.1029/2011JD016858, 2012.

Kok, J. F.: Does the size distribution of mineral dust aerosols depend on the wind speed at emission?, Atmos. Chem. Phys., 11, 1014910156, doi:10.5194/acp-11-10149-2011, 2011a.

Kok, J. F.: A scaling theory for the size distribution of emitted dust aerosols suggests climate models underestimate the size of the global dust cycle, P. Natl. Acad. Sci. USA, 108, 1016-1021, $2011 b$.

Kok, J. F., Parteli, E. J., Michaels, T. I., and Karam, D. B.: The physics of wind-blown sand and dust, Rep. Prog. Phys., 75, 106901, 2012.

Krishnamurthy, A., Moore, J. K., Mahowald, N., Luo, C., and Zender, C. S.: Impacts of atmospheric nutrient inputs on marine biogeochemistry, J. Geophys. Res.-Biogeosciences, 115, g01006, doi:10.1029/2009JG001115, 2010.

Lacis, A. A. and Mishchenko, M. I.: Climate forcing, climate sensitivity, and climate response: a radiative modeling perspective on atmospheric aerosols, in: Aerosol Forcing of Climate, edited by: Charlson, R. and Heintzenberg, J., Wiley, New York, p. 11-42, 1995.

Levin, Z., Ganor, E., and Gladstein, V.: The effects of desert particles coated with sulfate on rain formation in the eastern Mediterranean, J. Appl. Meteorol., 35, 1511-1523, 1996.

Li, J., Scinocca, J., Lazare, M., McFarlane, N., von Salzen, K., and Solheim, L.: Ocean Surface Albedo and Its Impact on Radiation Balance in Climate Models, J. Climate, 19, 6314-6333, doi:10.1175/JCLI3973.1, 2006.

Liao, H. and Seinfeld, J.: Radiative forcing by mineral dust aerosols: Sensitivity to key variables, J. Geophys. Res.-Atmos., 103, 31637-31645, 1998.

Loeb, N. G., Manalo-Smith, N., Kato, S., Miller, W. F., Gupta, S. K., Minnis, P., and Wielicki, B. A.: Angular distribution models for top-of-atmosphere radiative flux estimation from the Clouds and the Earth's Radiant Energy System instrument on the Tropical Rainfall Measuring Mission satellite. Part I: Methodology, J. Appl. Meteorol., 42, 240-265, 2003.

Lyapustin, A.: Atmospheric and geometrical effects on land surface albedo, J. Geophys. Res.-Atmos., 104, 4127-4143, 1999.

Maghrabi, A., Alharbi, B., and Tapper, N.: Impact of the March 2009 dust event in Saudi Arabia on aerosol optical properties, meteorological parameters, sky temperature and emissivity, Atmos. Environ., 45, 2164-2173, 2011.

Mahowald, N. M., Baker, A. R., Bergametti, G., Brooks, N., Duce, R. A., Jickells, T. D., Kubilay, N., Prospero, J. M., and Tegen, I.: Atmospheric global dust cycle and iron inputs to the ocean, Global Biogeochem. Cycles, 19, gB4025, doi:10.1029/2004GB002402, 2005.

Miller, R. and Tegen, I.: Climate response to soil dust aerosols, J. Climate, 11, 3247-3267, 1998.

Miller, R. L., Tegen, I., and Perlwitz, J.: Surface radiative forcing by soil dust aerosols and the hydrologic cycle, J. Geophys. Res.Atmos., 109, d04203, doi:10.1029/2003JD004085, 2004.

Mlawer, E. and Clough, S.: On the extension of rapid radiative transfer model to the shortwave region, in: Proceedings of the Sixth Atmospheric Radiation Measurement (ARM) Science
Team Meeting, 4-7 March 1996, San Antonio, Texas, Conf9603149, U.S. Dept. of Energy, Washington, D.C., 1997, p. 223 226, 1997.

Mlawer, E. J., Taubman, S. J., Brown, P. D., Iacono, M. J., and Clough, S. A.: Radiative transfer for inhomogeneous atmospheres: RRTM, a validated correlated-k model for the longwave, J. Geophys. Res., 102, 16663-16682, 1997.

Myhre, G., Myhre, C., Samset, B., and Storelvmo, T.: Aerosols and their Relation to Global Climate and Climate Sensitivity, Nature Education Knowledge, 4, 7, 2013.

Notaro, M., Alkolibi, F., Fadda, E., and Bakhrjy, F.: Trajectory analysis of Saudi Arabian dust storms, J. Geophys. Res.-Atmos., 118 , 6028-6043, 2013.

Osborne, S., Baran, A., Johnson, B., Haywood, J., Hesse, E., and Newman, S.: Short-wave and long-wave radiative properties of Saharan dust aerosol, Q. J. Roy. Meteorol. Soc., 137, 1149-1167, 2011.

Otto, S., de Reus, M., Trautmann, T., Thomas, A., Wendisch, M., and Borrmann, S.: Atmospheric radiative effects of an in situ measured Saharan dust plume and the role of large particles, Atmos. Chem. Phys., 7, 4887-4903, doi:10.5194/acp-7-4887-2007, 2007.

Prospero, J. M.: Assessing the impact of advected African dust on air quality and health in the eastern United States, Human and Ecological Risk Assessment: An International Journal, 5, 471479, 1999.

Prospero, J. M., Ginoux, P., Torres, O., Nicholson, S. E., and Gill, T. E.: Environmental characterization of global sources of atmospheric soil dust identified with the Nimbus 7 Total Ozone Mapping Spectrometer (TOMS) absorbing aerosol product, Rev. Geophys., 40, 1002, doi:10.1029/2000RG000095, 2002.

Roesch, A., Schaaf, C., and Gao, F.: Use of Moderate-Resolution Imaging Spectroradiometer bidirectional reflectance distribution function products to enhance simulated surface albedos, J. Geophys. Res.-Atmos, 109, d12105, doi:10.1029/2004JD004552, 2004.

Ryder, C. L., Highwood, E. J., Rosenberg, P. D., Trembath, J., Brooke, J. K., Bart, M., Dean, A., Crosier, J., Dorsey, J., Brindley, H., Banks, J., Marsham, J. H., McQuaid, J. B., Sodemann, H., and Washington, R.: Optical properties of Saharan dust aerosol and contribution from the coarse mode as measured during the Fennec 2011 aircraft campaign, Atmos. Chem. Phys., 13, 303 325, doi:10.5194/acp-13-303-2013, 2013.

Shao, Y., Ishizuka, M., Mikami, M., and Leys, J. F.: Parameterization of size-resolved dust emission and validation with measurements, J. Geophys. Res.-Atmos., 116, d08203, doi:10.1029/2010JD014527, 2011.

Shuai, Y., Schaaf, C. B., Strahler, A. H., Liu, J., and Jiao, Z.: Quality assessment of BRDF/albedo retrievals in MODIS operational system, Geophys. Res. Lett., 35, 105407, doi:10.1029/2007GL032568, 2008.

Sicard, M., Bertolín, S., Mallet, M., Dubuisson, P., and Comerón, A.: Estimation of mineral dust long-wave radiative forcing: sensitivity study to particle properties and application to real cases in the region of Barcelona, Atmos. Chem. Phys., 14, 9213-9231, doi:10.5194/acp-14-9213-2014, 2014.

Slingo, A., Ackerman, T. P., Allan, R. P., Kassianov, E. I., McFarlane, S. A., Robinson, G. J., Barnard, J. C., Miller, M. A., Harries, J. E., Russell, J. E., and Dewitte, S.: Observations of the impact of 
a major Saharan dust storm on the atmospheric radiation balance, Geophys. Res. Lett., 33, 124817, doi:10.1029/2006GL027869, 2006.

Sokolik, I. N. and Toon, O. B.: Incorporation of mineralogical composition into models of the radiative properties of mineral aerosol from UV to IR wavelengths, J. Geophys. Res.-Atmos., 104, 9423-9444, 1999.

Solomos, S., Kallos, G., Kushta, J., Astitha, M., Tremback, C., Nenes, A., and Levin, Z.: An integrated modeling study on the effects of mineral dust and sea salt particles on clouds and precipitation, Atmos. Chem. Phys., 11, 873-892, doi:10.5194/acp11-873-2011, 2011.

Strahan, S. E., Douglass, A. R., Stolarski, R. S., Akiyoshi, H., Bekki, S., Braesicke, P., Butchart, N., Chipperfield, M. P., Cugnet, D., Dhomse, S., Frith, S. M., Gettelman, A., Hardiman, S. C., Kinnison, D. E., Lamarque, J.-F., Mancini, E., Marchand, M., Michou, M., Morgenstern, O., Nakamura, T., Olivié, D., Pawson, S., Pitari, G., Plummer, D. A., Pyle, J. A., Scinocca, J. F., Shepherd, T. G., Shibata, K., Smale, D., Teyssèdre, H., Tian, W., and Yamashita, Y.: Using transport diagnostics to understand chemistry climate model ozone simulations, J. Geophys. Res.Atmos., 116, d17302, doi:10.1029/2010JD015360, 2011.

Tanaka, T. Y. and Chiba, M.: A numerical study of the contributions of dust source regions to the global dust budget, Global Planet. Change, 52, 88-104, 2006.

van de Hulst, H.: Light scattering by small particles, Courier Dover Publications, 31 East 2nd Street, Mineola, New York, 1957.

Vaughan, M. A., Young, S. A., Winker, D. M., Powell, K. A., Omar, A. H., Liu, Z., Hu, Y., and Hostetler, C. A.: Fully automated analysis of space-based lidar data: An overview of the CALIPSO retrieval algorithms and data products, in: Remote Sensing, p. 1630, International Society for Optics and Photonics, 2004.
Veihelmann, B., Konert, M., and van der Zande, W. J.: Size distribution of mineral aerosol: using light-scattering models in laser particle sizing, Appl. Optics, 45, 6022-6029, 2006.

Weinzierl, B., Petzold, A., Esselborn, M., Wirth, M., Rasp, K., Kandler, K., Schütz, L., Koepke, P., and Fiebig, M.: Airborne measurements of dust layer properties, particle size distribution and mixing state of Saharan dust during SAMUM 2006, Tellus B, 61, 96-117, 2009.

Wielicki, B. A., Barkstrom, B. R., Harrison, E. F., Lee III, R. B., Louis Smith, G., and Cooper, J. E.: Clouds and the Earth's Radiant Energy System (CERES): An earth observing system experiment, B. Am. Meteorol. Soc., 77, 853-868, 1996.

Yu, Y., Notaro, M., Liu, Z., Kalashnikova, O., Alkolibi, F., Fadda, E., and Bakhrjy, F.: Assessing temporal and spatial variations in atmospheric dust over Saudi Arabia through satellite, radiometric, and station data, J. Geophys. Res.-Atmos., 118, 1325313264, doi:10.1002/2013JD020677, 2013.

Zhang, L., Li, Q. B., Gu, Y., Liou, K. N., and Meland, B.: Dust vertical profile impact on global radiative forcing estimation using a coupled chemical-transport-radiative-transfer model, Atmos. Chem. Phys., 13, 7097-7114, doi:10.5194/acp-13-70972013, 2013.

Zhao, C., Chen, S., Leung, L. R., Qian, Y., Kok, J. F., Zaveri, R. A., and Huang, J.: Uncertainty in modeling dust mass balance and radiative forcing from size parameterization, Atmos. Chem. Phys., 13, 10733-10753, doi:10.5194/acp-13-10733-2013, 2013. 